\title{
Avaliação de propriedades mecânicas da madeira de Pinus taeda provenientes de placas de cross laminated timber
}

\author{
Evaluation of the mechanical properties of Pinus taeda \\ wood from cross laminated timber plates
}

\section{Ramon Vilela \\ Nilson Tadeu Mascia}

\section{Resumo}

A

s placas de madeira lamelada colada cruzada (em inglês, cross laminated timber [CLT]) vêm sendo utilizadas na construção civil devido a seu elevado desempenho arquitetônico e estrutural e por questões de sustentabilidade. Por ser um produto compósito ortotrópico, o conhecimento das características mecânicas de sua matéria prima nas direções em que são utilizadas é relevante para o projeto estrutural destas placas. O presente trabalho avalia os resultados experimentais de amostras extraídas de placas industrializadas de CLT produzidas com madeira da espécie Pinus taeda L. Foram realizados ensaios de compressão paralela e normal às fibras e ensaios de flexão. Verificou-se a conformidade da distribuição dos resultados experimentais com distribuições gaussianas. Foi utilizada a transformação de Johnson em resultados não compatíveis com a distribuição normal. Além disso, foram obtidos e discutidos coeficientes de correlação, valores característicos e classes de resistência de camadas do CLT. Identificou-se associação significativa entre as variáveis e um comportamento não linear na relação força $\times$ deslocamento de uma das amostras. Os resultados apresentados neste estudo podem ser empregados em projetos de placas de CLT considerando-se a diferença de materiais entre as camadas por métodos analíticos, numéricos ou de confiabilidade.

Palavras-chave: Madeira estrutural. Análise experimental. CLT. Compressão. Flexão.

\begin{abstract}
Cross Laminated Timber (CLT) plates are used in the construction industry both due to their high architectural and structural performance and for sustainability reasons. Because it is an orthotropic composite product, knowledge of the mechanical characteristics of its raw material in the directions of use is relevant to the structural design of such plates. This paper analyses the experimental results of samples extracted from industrialised CLT plates. The plates were produced with wood of the species Loblolly Pine (Pinus taeda L.). Compression tests parallel and perpendicular to the grain, as well as bending tests were carried out. The conformity of the results distribution with Gaussian distributions was verified. Johnson's transformation was used for results not compatible with the normal

distribution. In addition, the correlation coefficient, characteristic values and strength classes of CLT layers are presented and discussed. A significant association between the variables and nonlinear behaviour in the force $x$ displacement relationship of one of the samples was identified. The results presented in this study can be used in CLT plate design, considering the difference in materials between layers by analytical, numerical or reliability methods.
\end{abstract}

${ }^{1}$ Ramon Vilela ${ }^{1}$ Universidade Estadual de Campinas Campinas - SP - Brasil

${ }^{2}$ Nilson Tadeu Mascia Universidade Estadual de Campinas Campinas - SP - Brasil

Recebido em 27/02/20 Aceito em 15/03/21
Keywords: Structural wood. Experimental analysis. Cross laminated timber. Compression. Bending.

VILELA, R.; MASCIA, N. T. Avaliação de propriedades mecânicas da madeira de Pinus taeda provenientes de placas de 89 cross laminated timber. Ambiente Construído, Porto Alegre, v. 21, n. 4, p. 89-110, out./dez. 2021. ISSN 1678-8621 Associação Nacional de Tecnologia do Ambiente Construído. http: //dx.doi.org/10.1590/s1678-86212021000400560 


\section{Introdução}

Produtos de engenharia da madeira são aqueles que têm a madeira como principal matéria prima e que são utilizados na engenharia por terem melhores desempenhos mecânicos e menor variabilidade que sua matéria prima. Tais produtos vêm tendo grande espaço no mercado da construção civil em diversas partes do mundo (MANNINEN, 2014). A placa lamelada colada cruzada - mais conhecida pelo termo em inglês cross laminated timber (CLT) — é um produto de engenharia constituído por lamelas de madeira organizados em camadas que são coladas em duas ou mais direções (BUCK et al., 2016) comumente posicionadas a $90^{\circ}$ ou $0^{\circ}$ entre si (JELEČ́; VAREVAC; RAJČIĆ, 2018). Por ser um elemento estrutural de placa com baixo peso próprio e elevado desempenho estrutural, o CLT vem sendo utilizado como estrutura de placa (BAÑO et al., 2018; PEREIRA; CALIL JUNIOR, 2019) e elementos de parede (IZZI; POLASTRI; FRAGIACOMO, 2018). O CLT também atende aos requisitos de sustentabilidade por ter a madeira como sua principal matéria prima, que, por sua vez, é um material proveniente de fontes renováveis e altamente eficiente em questões de consumo energético e emissão de $\mathrm{CO}_{2}$ ao longo de seu processo de produção (MURTA et al., 2010).

No Brasil, o CLT é um produto relativamente novo e, atualmente, a empresa Crosslam Brasil é a responsável pela produção industrial de placas de CLT no país (OLIVEIRA, 2018). As placas são fabricadas com madeira da espécie Pinus taeda, que é uma espécie nativa dos Estados Unidos e que no Brasil é cultivada em áreas de reflorestamento com plantações em diversas regiões do país, com predominância da região sul e sudeste (INDÚSTRIA..., 2019; SCHULTZ, 1997).

A madeira é um material com propriedades mecânicas anisotrópicas (MASCIA; VANALLI, 2012), entretanto, para modelos elásticos de engenharia, pode ser considerada como um material linear ortotrópico (MASCIA; LAHR, 2006). Por ser produzido em camadas cruzadas de madeira, os painéis de CLT podem ser tratados com comportamento mecânico de um compósito plano ortotrópico. Portanto, é pertinente conhecer as características físicas e mecânicas da madeira em ambas as direções em que são utilizadas no CLT.

As propriedades mecânicas e físicas do Pinus taeda têm sido foco de estudos que demonstram que estas propriedades podem ter diferenças significativas em função de diversos fatores. A relação entre a idade e as propriedades mecânicas e anatômicas do Pinus taeda foi analisada por Bendtsen e Senft (1986) por meio de ensaios de flexão e compressão nos quais foram utilizados corpos de prova da Carolina do Norte de aproximadamente 30 anos de idade. Não obstante, Ballarin e Palma (2003) avaliaram as propriedades de resistência e rigidez do lenho juvenil e adulto de Pinus taeda de 37 anos proveniente do estado de São Paulo utilizando um ensaio de flexão estática. Constantes dielétricas da madeira de Pinus taeda de 34 anos de idade foram correlacionadas com seus respectivos módulos de elasticidade estáticos por meio de ensaios não destrutivos por Ballarin e Nogueira (2005), nos quais foram empregados corpos de prova originários do estado de São Paulo. Via ensaios de compressão e flexão, Jeong, Hindman e Zink-Sharp (2010) estudaram propriedades ortotrópicas do Pinus taeda de 25 anos de idade proveniente de Virginia, considerando o lenho juvenil e adulto. Na pesquisa realizada por Moya et al. (2013), foram determinadas características físicas e mecânicas de lenho juvenil e adulto de Pinus taeda com idade entre 15 e 25 anos oriundas de plantações uruguaias. Nessa pesquisa foram realizados ensaios de flexão, compressão paralela e normal às fibras, cisalhamento e determinação da densidade. As propriedades mecânicas de resistência à compressão e resistência ao embutimento da madeira de Pinus taeda foram comparadas por Almeida et al. (2014) a fim de estabelecer correlações entre ambas as propriedades.

Na Tabela 1 são apresentados os valores de módulo de elasticidade à flexão $\left(E_{M}\right)$ e compressão paralela às fibras $\left(E_{c 0}\right)$, resistência à compressão paralela às fibras $\left(f_{c 0}\right)$ e densidade a $12 \%$ de umidade $\left(\rho_{12 \%}\right)$ observados pela norma NBR 7190 (ABNT, 1997) e por diversos autores.

Em geral, as propriedades físicas e mecânicas da madeira de uma espécie são influenciadas por diversos fatores, tais como o local de cultivo da árvore, o local e a posição de extração do corpo de prova do troco, se no lenho do corpo de prova predomina a madeira juvenil ou a adulta, a idade da árvore, a presença de nós ou imperfeições (BODIG; JAYNE, 1982), a umidade e a inclinação das fibras (JEONG; HINDMAN; ZINKSHARP, 2010). Pela existência destes fatores, pode-se entender que é plausível que haja divergência dos resultados apresentados na Tabela 1 . No CLT, a distribuição destes fatores é utilizada para garantir maior produtividade e aproveitamento estratégico da matéria prima, podendo, por exemplo, haver lamelas de diferentes idades ou originárias de regiões diferentes compondo a mesma placa. Quanto à presença de nós e imperfeições, o processo produtivo do CLT inclui uma classificação visual ou mecânica para garantir 
critérios para a seleção das tábuas antes da lamelagem e aplicação do corte para os finger joints (AMERICAN...; AMERICAN..., 2018).

Outro aspecto inerente ao produto CLT é a impossibilidade de estabelecer a compatibilidade dos eixos radial (R) e tangencial (T) da madeira com uma única direção no CLT devido ao tamanho das lamelas frente ao da seção transversal do tronco (Figura 1). Porém, para critérios de projeto, é possível determinar valores característicos que representem o comportamento mecânico dos materiais utilizados, garantindo que estes estejam a favor da segurança.

Para a simulação e análise do comportamento estrutural de painéis de CLT, é necessário ter um conhecimento adequado sobre a madeira empregada para sua produção. No Brasil, a principal matéria prima utilizada para produzir o CLT atualmente é o Pinus taeda. Como este material provém de diversas regiões do país e tem diferentes propriedades, é importante verificar a normalidade de suas propriedades mecânicas, a linearidade de suas deformações sob carregamento, a intensidade da correlação entre suas variáveis e se existe compatibilidade entre as classes normativas (utilizadas no cálculo estrutural) e as propriedades do material.

Neste contexto, o presente trabalho tem os seguintes objetivos:

(a) avaliar as propriedades e o comportamento mecânico de corpos de prova de Pinus taeda extraídos de placas de CLT;

(b) estabelecer uma correlação entre propriedades físicas e mecânicas dos corpos de prova; e

(c) identificar a classificação do material segundo as normas NBR 7190 (ABNT, 1997) e BS EN 338 (COMITÉ..., 2016a).

Tabela 1 - Resumo de resultados de propriedades mecânicas e física da madeira de Pinus taeda obtidos pela norma NBR 7190 e por diversos autores

\begin{tabular}{l|c|c|c|c|c|c|c|c|c}
\hline \multirow{2}{*}{ Referência } & \multirow{2}{*}{$\begin{array}{c}\text { Idade } \\
\text { (anos) }\end{array}$} & $\begin{array}{c}\text { Média } \\
(\mathrm{MPa})\end{array}$ & $\begin{array}{c}\mathbf{C V} \\
(\%)\end{array}$ & $\begin{array}{c}\text { Média } \\
(\mathrm{MPa})\end{array}$ & $\begin{array}{c}\mathbf{C V} \\
(\%)\end{array}$ & $\begin{array}{c}\text { Média } \\
(\mathrm{MPa})\end{array}$ & $\begin{array}{c}\mathbf{C V} \\
(\%)\end{array}$ & $\begin{array}{c}\text { Média } \\
\left(\mathrm{kg} / \mathrm{m}^{3}\right)\end{array}$ & $\begin{array}{c}\mathbf{C V} \\
(\%)\end{array}$ \\
\hline NBR 7190 $^{1}$ & Não informado & - & - & 13.304 & - & 44,4 & 18,0 & 645 & - \\
Almeida $^{2}$ & Não informado & - & - & - & - & 27,4 & 11,0 & - & - \\
Bendtsen $^{3}$ & 13 & 10.577 & 22,8 & - & - & 24,2 & - & 600 & 9,3 \\
Moya $^{4}$ & $15-25$ & 7.444 & 33,7 & - & - & 37,2 & 25,3 & 488 & 13,3 \\
Jeong $^{5}$ & 25 & - & - & 2.530 & 31,7 & 23,5 & 31,1 & 440 & 7,2 \\
Ballarin $^{6}$ & 34 & - & - & 10.897 & 32,2 & - & - & 555 & 8,8 \\
Ballarin $^{7}$ & 37 & - & - & 13.812 & 26,8 & 107,0 & 26,6 & 605 & 14,6 \\
\hline
\end{tabular}

Fontes: ${ }^{1}$ ABNT (1997), ${ }^{2}$ Almeida et al. (2014), ${ }^{3}$ Bendtsen e Senft (1986), ${ }^{4}$ Moya et al. (2013), Jjeong, Hindman e ZinkSharp (2010), ${ }^{6}$ Ballarin e Palma (2003) e ${ }^{7}$ Ballarin e Nogueira (2005).

Nota: CV: coeficiente de variação.

Figura 1 - Direções dos anéis de crescimento no tronco e na lamela de madeira, sendo b a largura e $h$ a altura da lamela

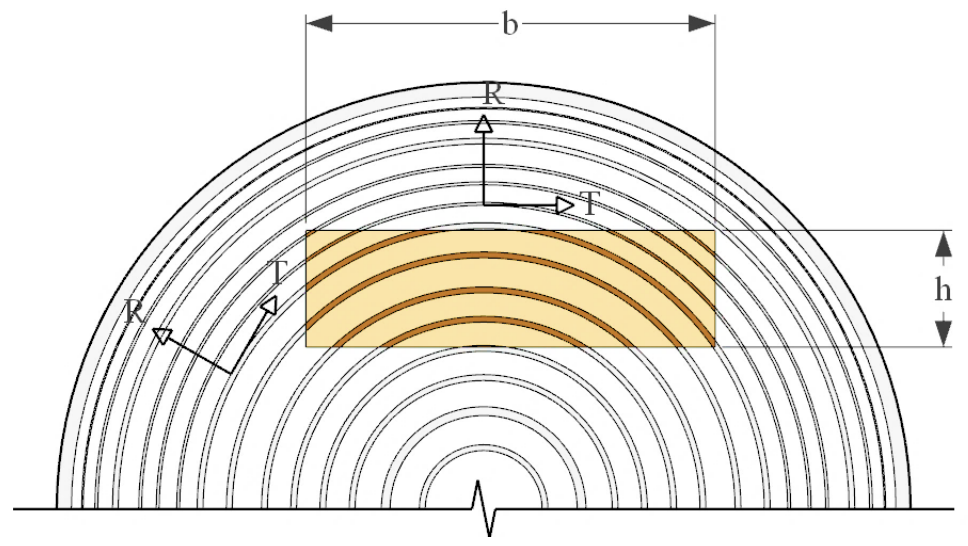


As hipóteses consideradas neste estudo são que as propriedades mecânicas e de densidade da madeira de Pinus taeda podem ser representadas por curvas de distribuição normal, que as deformabilidades nas direções paralela e normal às fibras são inicialmente lineares, que existem correlações significantes entre as propriedades mecânicas e de densidade da madeira de Pinus taeda e que essas propriedades podem ser caracterizadas e representadas por classes de resistência conforme as normas NBR 7190 (ABNT, 1997) e/ou BS EN 338 (COMITÉ..., 2016a).

\section{Materiais e métodos}

\section{Amostras}

Os 48 corpos de prova empregados nesta pesquisa foram extraídos de camadas de placas de CLT, sendo que 16 deles foram destinados a ensaios de flexão simples, 16 foram utilizados em ensaios de compressão paralela às fibras e 16 foram avaliados experimentalmente em ensaios de compressão normal às fibras. Destaca-se que a quantidade de corpos de prova para cada tipo de ensaio atende ao requisito mínimo de 12 corpos de prova estabelecido pela NBR 7190 (ABNT, 1997).

A extração dos corpos de prova foi executada com serra circular de mão. As sete placas das quais foram extraídos os corpos de prova para análise tinham dimensões de $800 \mathrm{~mm}$ de largura, $2800 \mathrm{~mm} \mathrm{de}$ comprimento e $160 \mathrm{~mm}$ de espessura total, sendo esta composta por cinco camadas de 40L-20T-40L-20T$40 \mathrm{~L}^{1}$ de espessura. As placas foram previamente ensaiadas à flexão estática em quatro pontos unidirecional. Houve ruptura de cinco placas por fraturas na camada inferior ao centro de placa, onde havia ligações de topo do tipo finger joints nas lamelas, sendo que, em algumas, essas fissuras se propagaram para camadas acima. Tais rupturas foram caracterizadas devido ao momento fletor excessivo. Duas outras placas tiveram sua ruptura caracterizada pelo cisalhamento no efeito rolling shear. Levando isto em consideração, determinou-se que os corpos de prova utilizados neste estudo fossem extraídos de regiões onde o momento fletor não foi máximo e que não apresentavam sinais de comprometimento das lamelas. A Figura 2 mostra uma imagem do ensaio realizado de flexão em placas biapoiadas: em verde, destaca-se a região de onde foram retirados os corpos de prova para caracterização; em vermelho, destaca-se a região em que foram observados sinais de fratura.

Figura 2 - Regiões da placa de CLT de onde foram extraídas as amostras para caracterização do material

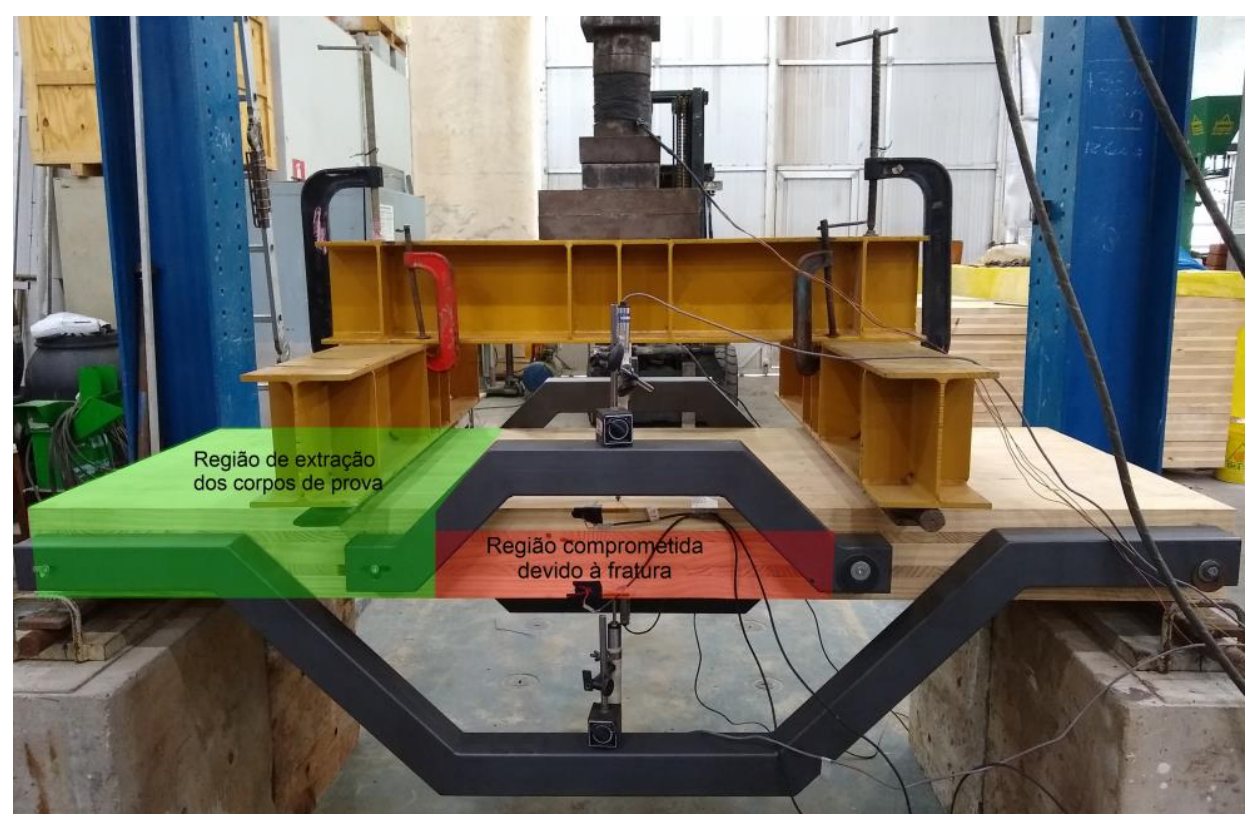

${ }^{1} \mathrm{~L}$ representa as camadas com fibras no sentido principal da placa e $\mathrm{T}$, as camadas com fibras no sentido transversal a este. Medidas em milímetros.

92 Vilela, R.; Mascia, N. T. 
Os corpos de prova para avaliação à flexão estática e compressão paralela às fibras foram retirados de camadas externas. Por sua vez, os corpos de prova destinados à compressão normal às fibras foram extraídos de camadas internas das placas que não apresentaram ruptura devido ao esforço cortante (i.e., que tinham fraturas de rolling shear). Observa-se que, quando flexionadas em uma única direção, as camadas principais sofrem tensões normais na direção paralela às fibras, enquanto as camadas transversais estão sujeitas a tensões normais na direção perpendicular às fibras.

Na Figura 3 é mostrada parte de uma das placas de CLT de onde foram extraídos os corpos de prova e se indica a nomenclatura das camadas e a direção principal utilizadas neste trabalho.

As placas de CLT foram produzidas industrialmente pela empresa Crosslam. No processo produtivo, os lotes de lamelas são previamente classificados por amostragem utilizando o método não destrutivo de ultrassonografia para aferir o módulo de elasticidade longitudinal da madeira. Após a remoção de excesso de nós e de defeitos naturais da madeira, emendas de topo finger joints são utilizadas para dar maior comprimento às lamelas. As lamelas de maior rigidez são destinadas às camadas externas, enquanto as de menor rigidez e maior quantidade de nós são posicionas nas camadas internas. Esta divisão de materiais pode ser observada pela densidade e o espaçamento dos anéis de crescimento retratados na Figura 3.

A distribuição das lamelas por camadas em função da rigidez e da presença de nós é adotado por questões de eficiência estrutural, pois materiais mais rígidos posicionados mais distantes do centro de gravidade de uma seção transversal produzem momento de inércia maior em comparação a uma seção com lamelas posicionadas aleatoriamente ao longo da seção. Além disto, este procedimento também possibilita a utilização de matérias primas com classes de resistência e densidade inferiores, posicionando-as em regiões onde os esforços normais devido à flexão são menores e de baixa influência para a rigidez do CLT, reduzindo o custo e a densidade do produto.

\section{Determinação da densidade aparente}

A massa de cada corpo de prova (M) foi obtida utilizando balança digital da marca Marte ${ }^{\circledR}$ modelo AS 5600, que tem capacidade de $5000 \mathrm{~g}$ e resolução de $0,1 \mathrm{~g}$. O volume dos corpos de prova (V) foi determinado pela média das dimensões geométricas em, no mínimo, dois pontos para dimensões menores que $100 \mathrm{~mm}$ e em seis pontos para as demais dimensões. As dimensões foram aferidas com paquímetro com resolução de $0,02 \mathrm{~mm}$. A densidade aparente foi determinada pela razão entre a massa e o volume em umidade aproximadamente a $12 \%\left(\rho_{a p}=M_{U} / V_{U}\right)$.

\section{Determinação do teor de umidade}

A umidade das amostras foi obtida por ensaio não destrutivo utilizando um aparelho leitor de umidade através de indução elétrica por contato da marca Merlin ${ }^{\circledR}$ modelo PM1-E, que tem resolução de $0,1 \%$ de umidade $^{2}$.

\section{Figura 3 - Seção da placa de CLT e nomenclaturas das camadas}

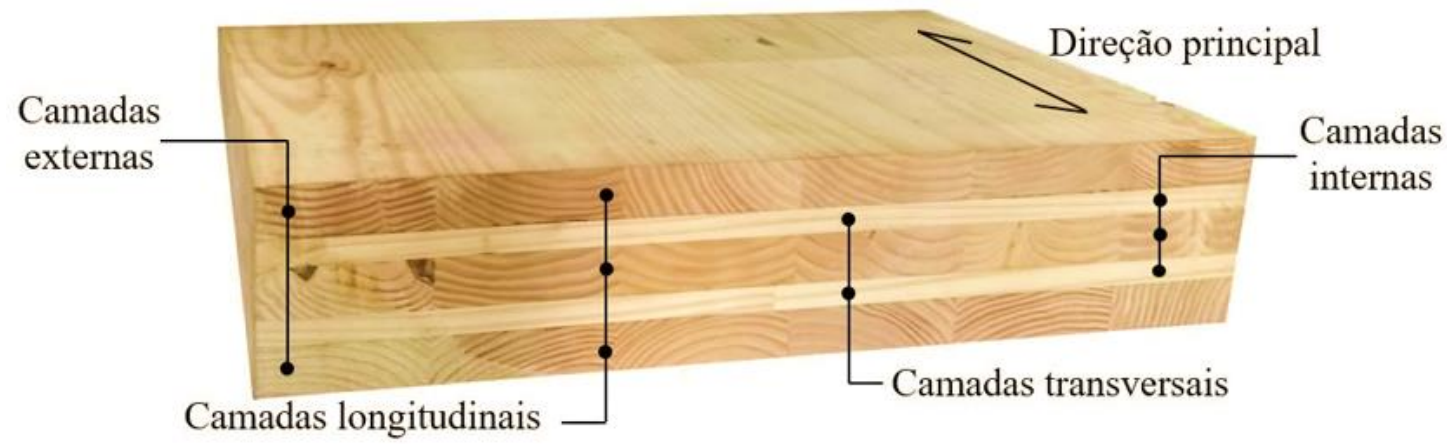

\footnotetext{
${ }^{2}$ Apesar de não ser o método indicado pela NBR 7190 (ABNT, 1997), estudos demonstram as propriedades de resistência elétrica da madeira e sua umidade podem ser correlacionadas a partir de fatores de correção (MILOTA, 1994; GILLIS; STEPHENS; PERALTA, 2001; LI et al., 2013). Não obstante, Ruy et al. (2018) apresentam em sua metodologia o monitoramento da umidade da madeira por meio de um
} instrumento de medição de capacitância por indução elétrica de mesma marca e modelo utilizado na condução deste estudo. 
O aparelho foi configurado para a constante dielétrica de madeira de pinus, e a densidade aparente de cada corpo de prova foi empregada para realizar a leitura das umidades à profundidade equivalente ao centro da seção transversal. As leituras foram realizadas nas quatro faces ao redor das fibras de cada corpo de prova. Estes ensaios foram desenvolvidos imediatamente antes da execução dos ensaios mecânicos de cada amostra a fim de representar mais precisamente a condição de umidade de cada corpo de prova naquele instante.

Para determinar os valores característicos de resistência e módulo de elasticidade, foram utilizados os valores estimados com umidade a $12 \%$. A correção dos valores de resistência de cada corpo de prova com umidade aferida para a umidade de $12 \%$ foi realizada de acordo com a NBR 7190 (ABNT, 1997). De modo semelhante, os valores de módulo de elasticidade foram corrigidos para umidade de $12 \%$.

\section{Valor característico inferior}

Em engenharia, o valor característico inferior da propriedade de um conjunto amostral é estabelecido pela probabilidade de $95 \%$ de novos valores obtidos em ensaios serem maiores que ele. Neste estudo, o valor característico inferior foi estabelecido para propriedades de densidade, rigidez ou resistência na madeira. A madeira das camadas externas e internas das placas de CLT foi caracterizada conforme as normas NBR 7190 (ABNT, 1997) e BS EN 14358 (COMITÉ..., 2016b) a fim de classificá-la pelos parâmetros de cada norma. Como foram levantados 16 resultados de resistência e rigidez de cada grupo de ensaio, os valores máximos foram descartados para a caracterização segundo a norma brasileira.

Para efeitos de comparação, as amostras também foram caracterizadas conforme a norma europeia BS EN 14358 (COMITÉ..., 2016b), que propõe a Equação 1 para estimar o valor característico das propriedades físicas e mecânicas da madeira.

$m_{k}=\bar{X}-k_{s}(n) s_{X}$

Eq. 1

Sendo:

$m_{k}$ o valor característico a ser calculado de resistência ou densidade;

$\bar{X}$ a média aritmética dos dados;

$s_{X}$ o desvio padrão indicado pela Equação 2; e

$k_{s}(n)$ é o fator estatístico para estimar o quantil inferior (5\%) indicado pela Equação 3 e 4 para resistência e rigidez, respectivamente.

$s_{X}=\max \left\{\begin{array}{c}\sqrt{\frac{1}{n-1} \sum_{i=1}^{n}\left(X_{i}-\bar{X}\right)^{2}} \\ 0,05 \bar{X}\end{array}\right.$

$k_{S}(n)=\frac{2,7 n+16}{1,6 n+7}$

$k_{S}(n)=\frac{0,25 n+12}{5 n+18}$

Eq. 4

Sendo:

$n$ o número de corpos de prova da amostra;

$X_{i}$ o valor da propriedade do $i$-ésimo corpo de prova; e

$\bar{X}$ a média aritmética da amostra.

Para distribuições de resistência e densidade, o fator $k_{s}(n)$ pode ser simplificadamente obtido pela Equação 3 , e para rigidez, o mesmo pode ser estabelecido pela Equação 4.

\section{Ensaio de flexão simples}

O ensaio de flexão para a avaliação da resistência e da rigidez seguiu os critérios e os procedimentos estabelecidos na NBR 7190 (ABNT, 1997). Os corpos de prova foram produzidos com dimensões nominais de $40 \mathrm{~mm} \times 40 \mathrm{~mm} \times 920 \mathrm{~mm}$. O ensaio foi executado utilizando uma prensa universal da marca EMIC ${ }^{\circledR}$, modelo DL30000. Os apoios fixos foram posicionados a $40 \mathrm{~mm}$ das faces dos corpos de prova, produzindo um vão livre $l_{0}=840 \mathrm{~mm}$. O atuador foi posicionado no centro do vão (Figura 4). 
Figura 4 - Ensaio de flexão simples

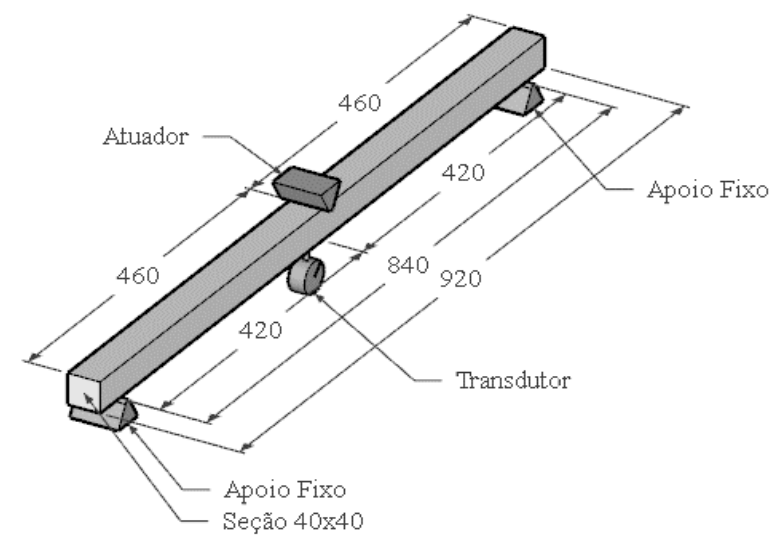

(a) Dimensões e esquema estático (em milímetros)

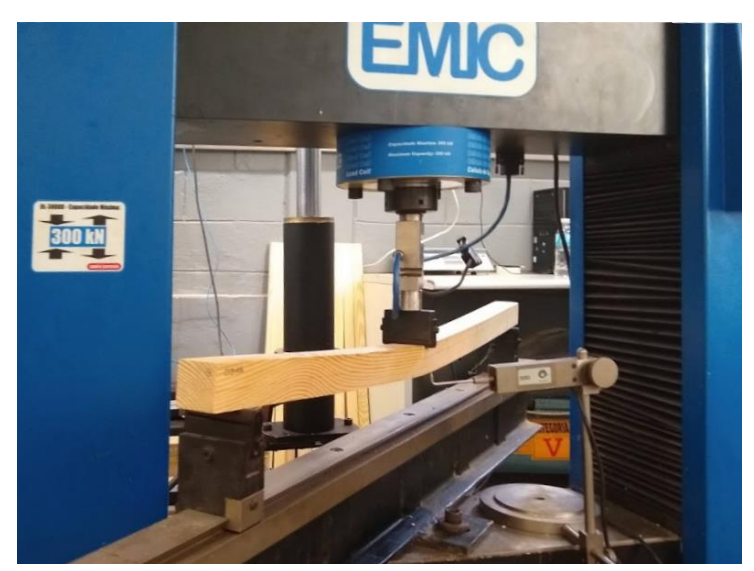

(b) Fotografia do ensaio

O carregamento foi conduzido com taxa de $10 \mathrm{MPa} / \mathrm{min}$ (equivalente a $508 \mathrm{~N} / \mathrm{min}$ ). Foram utilizados dois ciclos de carga, sendo o carregamento aplicado monoliticamente até $50 \%$ da carga máxima estimada, seguido de um intervalo de $30 \mathrm{~s}$, decréscimo de carregamento com taxa de $10 \mathrm{MPa} / \mathrm{min}$ até $10 \%$ da carga máxima estimada e novamente um intervalo de $30 \mathrm{~s}$. Após o primeiro ciclo de carga, aplicou-se o carregamento monotônico com taxa de $10 \mathrm{MPa} / \mathrm{min}$ até a ruptura do corpo de prova, conforme recomendado pela norma NBR 7190 (ABNT, 1997). A ruptura na flexão, por ser frágil, foi determinada pela fissura e pela queda brusca de carregamento durante sua aplicação. O transdutor de deslocamento vertical foi retirado quando o deslocamento atingia aproximadamente $10 \mathrm{~mm}$, a fim de preservar o equipamento.

O ensaio de flexão em três pontos é justificado pela razão entre o vão livre e a altura dos corpos de prova ser $l_{0} / h=21$. Usualmente, a relação entre módulos de elasticidade longitudinal e transversal da madeira são compreendidos entre $12 \leq E / G \leq 20$. Nestas condições de contorno, dimensões e rigidezes, o esforço cortante é responsável por produzir um deslocamento no centro do vão entre $3 \%$ a $5 \%$ do deslocamento total, sendo considerado desprezível, o que permite a obtenção do módulo de elasticidade no ensaio de flexão em três pontos (ALBINO, 2013).

As expressões para o cálculo do módulo de elasticidade e resistência dos corpos de prova são as descritas no Anexo B da NBR 7190 (ABNT, 1997). Cabe ressaltar que o módulo de elasticidade à flexão é calculado pela norma brasileira a partir dos deslocamentos entre $10 \%$ e $50 \%$ do carregamento máximo de cada corpo de prova.

\section{Ensaio de compressão normal às fibras}

Os ensaios de compressão normal às fibras foram realizados conforme a norma BS EN 408 (COMITÉ..., 2010). As dimensões nominais dos corpos de prova foram de $40 \mathrm{~mm} \times 60 \mathrm{~mm} \times 80 \mathrm{~mm}$. O carregamento foi aplicado nos corpos de prova com taxa de incremento constante, observando o tempo estimado de duração de $(300 \pm 120 \mathrm{~s})$ em função do carregamento máximo estimado. Neste ensaio não foram utilizados ciclos de carga, sendo o carregamento aplicado até a ruptura do corpo de prova, caracterizado pelo máximo valor de carregamento obtido pelo aquisitor. Foram empregados dois extensômetros mecânicos de $50 \mathrm{~mm}$ de comprimento de referência posicionados na face da paralela às fibras (Figura 5), sendo os mesmos removidos com carregamento de $70 \%$ do carregamento máximo estimado, garantindo-se desta maneira a integridade dos equipamentos.

A resistência à compressão normal às fibras foi determinada pela Equação 5 .

$f_{c 90}=\frac{P_{\text {máx }, e s t}}{b h}$

Sendo $P_{\text {máx,est }}$ a força máxima estimada, que deve ser determinada pelo ponto de convergência da curva carregamento $\times$ deformação com uma reta formada pela interseção entre os pontos $P_{40 \%}$ e $P_{10 \%}$ deslocada a $1 \%$ de $h_{0}$ (Figura 6); bh são as dimensões da seção transversal à direção do carregamento. 
Figura 5 - Ensaio de compressão normal às fibras

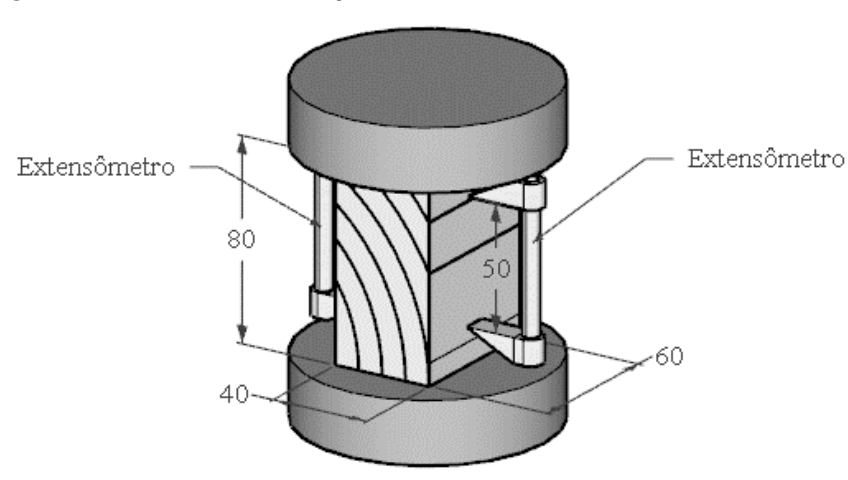

(a) Dimensões e esquema estático do ensaio (em milímetros)

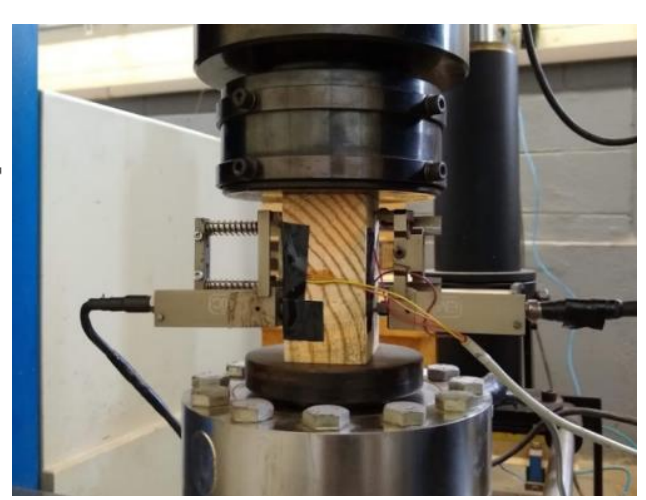

(b) Fotografia do ensaio

Figura 6 -Diagrama para determinar o máximo carregamento estimado à compressão normal às fibras

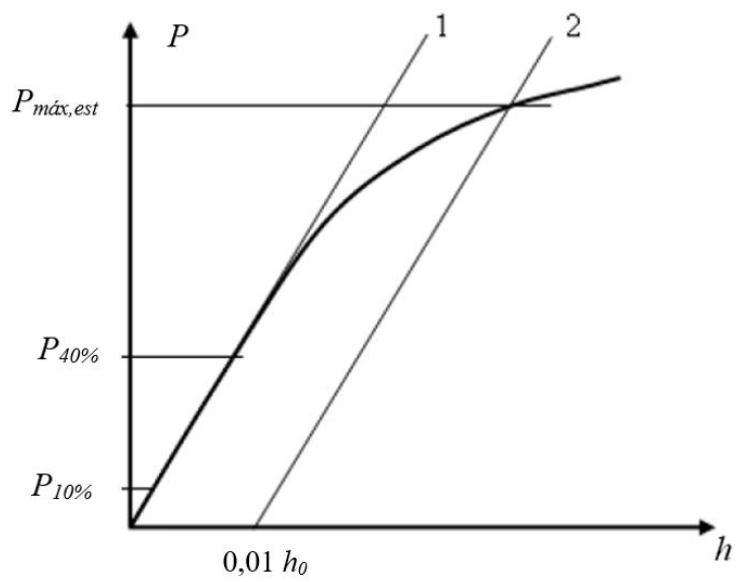

Fonte: Comité Européen de Normalization (2010, p. 28).

O módulo de elasticidade à compressão normal às fibras foi obtido a partir da Equação 6.

$E_{c}=\frac{\left(P_{40 \%}-P_{10 \%}\right) l_{0}}{\left(\delta_{40 \%}-\delta_{10 \%}\right) b h}$

Eq. 6

Sendo:

$E_{c}$ equivalente a $E_{c 90}$ para o módulo de elasticidade à compressão normal e $E_{c 0}$ para o módulo de elasticidade à compressão paralela às fibras;

$P_{40 \%}$ e $P_{10 \%}$ as forças a $40 \%$ e $10 \%$ da força máxima estimada, respectivamente;

$l_{0}$ o comprimento de referência do extensômetro;

$\delta_{40 \%}$ e $\delta_{10 \%}$ os deslocamentos no extensômetro correspondentes a $P_{40 \%}$ e $P_{10 \%}$, respectivamente; e

$b h$ as dimensões da seção transversal à direção do carregamento.

Salienta-se que, para a norma europeia BS EN 408 (COMITÉ..., 2010), os módulos de elasticidade à compressão paralela ou normal às fibras são calculados a partir dos deslocamentos devido aos carregamento de $10 \%$ e $40 \%$ do carregamento máximo, diferentemente da norma brasileira.

\section{Ensaio de compressão paralela às fibras}

Os ensaios de compressão paralela às fibras foram realizados conforme a norma BS EN 408 (COMITÉ..., 2010). As dimensões nominais dos corpos de prova submetidos à compressão paralela às fibras estão apresentadas na Figura 7, sendo o comprimento seis vezes a largura. Os extensômetros mecânicos tinham o comprimento de referência $l_{0}=150 \mathrm{~mm}$. 
Figura 7 - Ensaio de compressão paralela às fibras

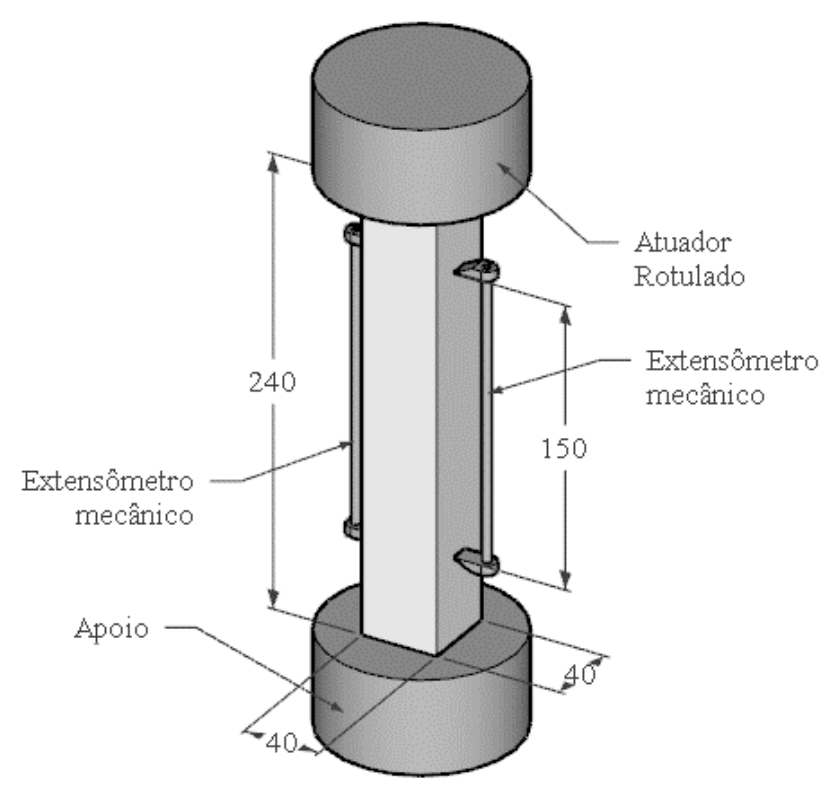

(a) Dimensões e esquema do ensaio (em milímetros)

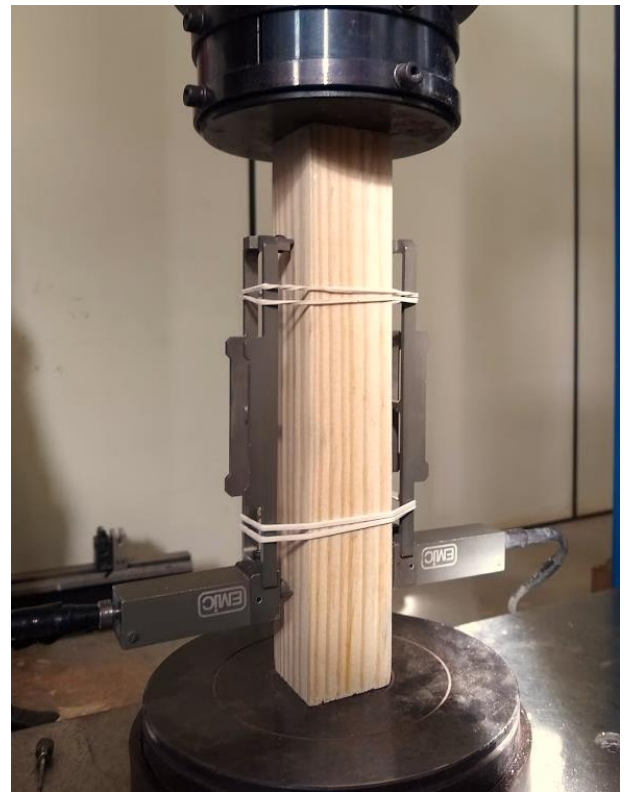

(b) Fotografia do ensaio

Neste ensaio, o carregamento foi aplicado com taxa de $0,12 \mathrm{~mm} / \mathrm{s}$, sem a utilização de ciclos de carga, até atingir a ruptura do corpo de prova. Na compressão paralela às fibras, a ruptura é caracterizada pelo máximo valor de carregamento. As fissuras só se evidenciaram com o incremento de deformação. Os extensômetros utilizados foram posicionados em laterais paralelas, sendo removidos com carregamento de $70 \%$ do carregamento máximo estimado, a fim de garantir a integridade do equipamento. Inicialmente, o carregamento máximo foi estimado em função da resistência média do Pinus taeda informado pelo anexo E da NBR 7190 (ABNT, 1997), sendo $f_{c 0}=44,4 \mathrm{MPa}$. Durante os ensaios, as resistências eram comparadas ao valor estimado para que, caso houvesse um desvio maior a $20 \%$, o carregamento estimado seria corrigido para que os equipamentos não fossem danificados.

A resistência à compressão paralela às fibras foi determinada pela Equação 7.

$f_{c 0}=\frac{P_{\text {máx }}}{b h}$

Sendo:

$P_{\text {máx }}$ a máxima carga aplicada no corpo de prova; e

$\mathrm{b}$ e $\mathrm{h}$ as dimensões da seção transversal.

O módulo de elasticidade à compressão paralela às fibras foi obtido empregando a Equação 6 .

Os coeficientes de Poisson, que correlacionam as deformações especificas em uma direção perpendicular à direção do carregamento, foram determinados conforme Equação 8.

$v_{12}=-\frac{\varepsilon_{2}}{\varepsilon_{1}}$

Sendo:

$\varepsilon_{2}$ a deformação específica passiva na direção ortogonal ao carregamento; e

$\varepsilon_{1}$ a deformação específica na direção do carregamento.

No caso, o índice 1 corresponde à direção longitudinal L e o índice 2 corresponde à direção tangencial T ou à radial $\mathrm{R}$.

As deformações específicas foram aferidas em cinco corpos de prova instrumentados com extensômetros de resistência elétrica da marca Kyowa ${ }^{\circledR}$, modelo KFGS-5-120-C1-5, com 119,8 $\Omega \pm 0,2 \%$ e 5 mm de comprimento, posicionado no centro das faces avaliadas, conforme mostra a Figura 8. 
Figura 8 - Corpos de prova de compressão paralela e normal às fibras instrumentados com extensômetros

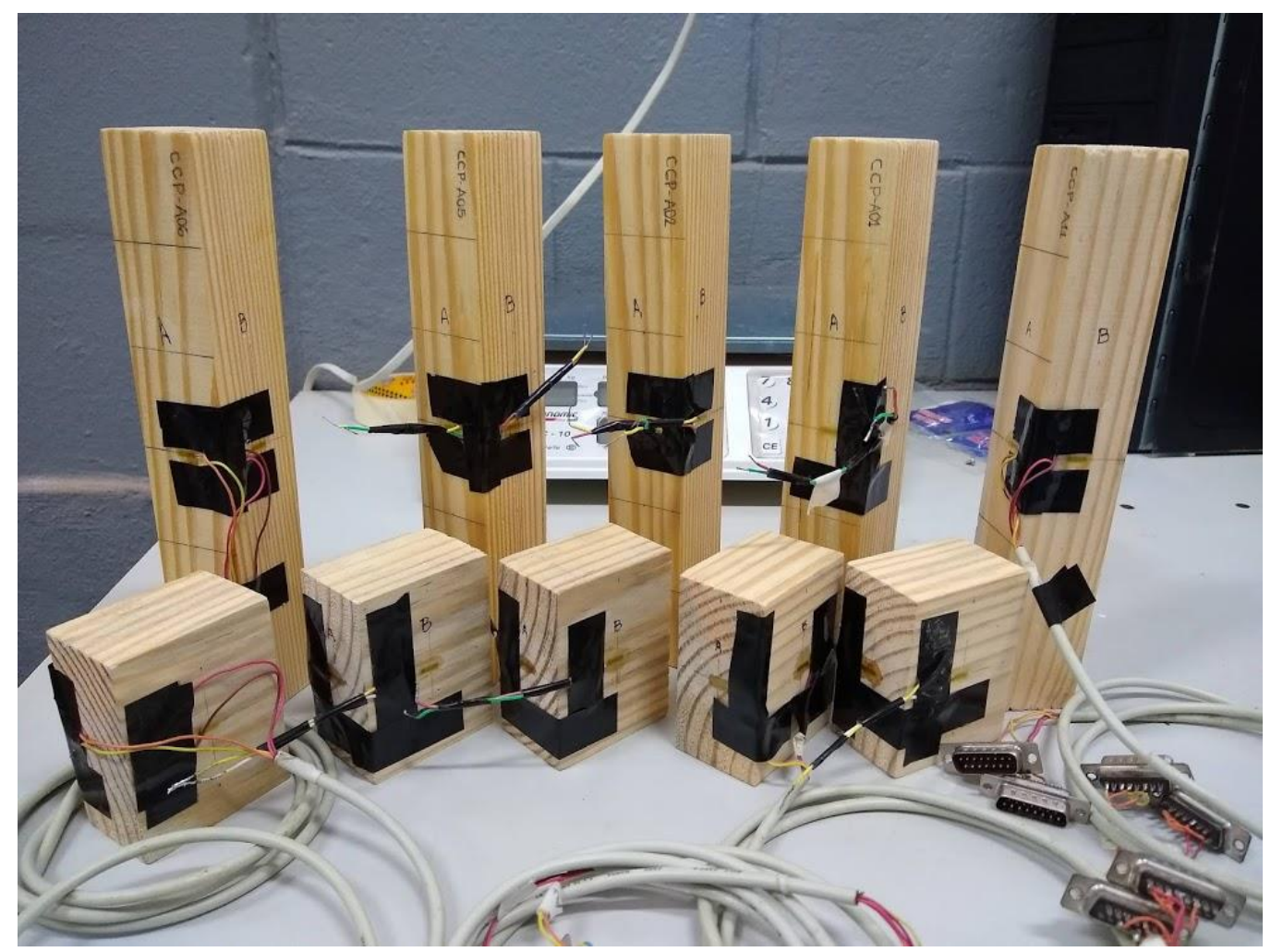

\section{Procedimentos estatísticos}

Foi realizado o teste de normalidade para os dados de densidade, umidade, resistência e elasticidade, além de coeficientes de Poisson pelo método de Anderson-Darling (ANDERSON; DARLING, 1952), pelo qual se determinou o P-Value para um nível de significância de $\alpha=0,05$. Este procedimento foi realizado com auxílio do software estatístico Minitab ${ }^{\circledR} 16$ (RYAN; CRYER; JOINER, 2013). Para os resultados que não apresentaram concordâncias com uma distribuição normal, foram realizados testes com as seguintes distribuições: Lognormal, Lognormal de três parâmetros, Logística, Loglogística, Loglogística de três parâmetros, Máximos Valores Extremos, Mínimos Valores Extremos, Gama, Gama de três parâmetros, Exponencial, Exponencial de dois parâmetros, Weibull, Weibull de três parâmetros, transformação de BoxCox e transformação de Johnson.

O teste $\mathrm{t}$ two-sample foi utilizado para avaliar a diferença entre as médias de resultados obtidos neste estudo e aqueles apresentados pela literatura consultada (Tabela 1). O índice de confiança estabelecido para este teste foi de $95 \%$, sendo o índice de significância $\alpha=0,05$. Foi estipulada a equivalência entre médias para a hipótese nula $\left(H_{0}: \mu_{1}=\mu_{2}\right)$ e a não equivalência como hipótese alternativa $\left(H_{1}: \mu_{1} \neq \mu_{2}\right)$. Assim, ao obter-se um $P$-Value maior que $\alpha$, é aceita a $H_{0}$ e rejeitada a $H_{1}$.

A transformação de Johnson (1949) é um método matemático empregado para ajustar dados com uma distribuição não normal para uma distribuição normal. Para este procedimento, é encontrada uma das três famílias propostas pelo método de acordo com a função discriminadora, conforme Equação 9.

$F_{D}=\frac{m n}{p^{2}}$

Eq. 9

Sendo $m=X_{3 Z}-X_{Z} ; n=X_{-Z}-X_{-3 Z} ; p=X_{Z}-X_{-Z}$.

$\mathrm{O}$ valor $Z$ está relacionado ao tamanho da amostra a ser transformada. Por sua vez, este é escolhido inicialmente como sendo $Z>0$ e dificilmente será maior que 1 , sendo geralmente próximo a 0,5 . Ao estimar $Z$, são definidas as probabilidades acumuladas $\phi(-3 Z), \phi(-Z), \phi(Z)$ e $\phi(3 Z)$ para as funções de distribuição acumulada da normal padrão $\phi$. Ao ordenar $X_{(1)} \leq X_{(2)} \ldots \leq X_{(n)}$ para cada valor de $\xi=-3 Z$, 
$-Z, Z$ e $3 Z$, são encontrados os percentis $X_{(i)}$ que correspondem a $\phi(\xi)$, ficando $X \xi=X_{(i)}$. Uma condição do método é que a função $\phi(\xi)$ atenda à Equação 10.

$\phi(\xi)=\frac{i-0,5}{n}$

Eq. 10

Seleciona-se a família $S_{U}$ quando $F_{D}>1$, escolhe-se a família $S_{B}$ para $F_{D}<1$ e, para $F_{D}=1$, deve-se selecionar a família $S_{L}$. As famílias para o algoritmo de transformação de Johnson estão descritas na Tabela 2.

Os parâmetros da transformação de Johnson foram calculados com auxílio do software Minitab ${ }^{\circledR}$ 16. Para resgatar os valores produzidos pela transformação de Johnson para a família $S_{L}$, isola-se $X$, chegando na expressão observada na Equação 11.

$X^{*}=\exp \left(\frac{Y-\gamma}{\eta}\right)+\varepsilon$

Sendo:

$Y$ o dado alterado pela transformação de Johnson;

$\gamma, \eta$ e $\varepsilon$ os parâmetros constantes da família $S_{L}$; e

$X^{*}$ o valor de retorno com probabilidade na distribuição originalmente não normal equivalente a probabilidade do valor $Y$ em uma distribuição normal.

O coeficiente de correlação de Pearson foi utilizado neste trabalho para avaliar a correlação linear entre pares de variáveis. Este valor pode variar de -1 a 1 , sendo que, quanto maior for o valor absoluto do coeficiente de correlação, maior será a influência da variação de uma variável sobre a outra. O coeficiente de correlação de Pearson é calculado conforme a Equação 12.

$r_{x y}=\frac{\sum_{i=1}^{n}\left(x_{i}-\bar{x}\right)\left(y_{i}-\bar{y}\right)}{\sqrt{\sum_{i=1}^{n}\left(x_{i}-\bar{x}\right)^{2}} \sqrt{\sum_{i=1}^{n}\left(y_{i}-\bar{y}\right)^{2}}}$

Eq. 12

Sendo:

$x_{i}$ e $y_{i}$ os elementos de duas variáveis distintas;

$\bar{x}$ e $\bar{y}$ os valores médios das variáveis; $\mathrm{e}$

$n$ o número de elementos das variáveis.

O teste ANOVA One-Way foi aplicado nos resultados de umidade aferidos das diferentes amostras a fim de verificar se existem diferenças significativas entre as variâncias. Neste procedimento, caso a condição F-Value $\leq F_{\text {crítico }}$ não seja verificada, descarta-se a hipótese nula (na qual as variâncias são iguais). Nesta ocasião, realizou-se uma análise post hoc pelo método Bonferroni (1936) a fim de verificar quais amostras apresentam diferenças significativas. Nesta última análise, quando a Equação 13 é verificada, considera-se que a diferença entre as amostras $x$ e $y$ é significante.

$p_{x y} \leq \frac{a}{m}$

Eq. 13

Sendo:

$\alpha$ o nível de significância (neste caso, igual a 0,05 ); e

$m$ o número de amostras (neste caso, igual a 3 ).

Tabela 2 - Famílias, funções e intervalos da transformação de Johnson (1949)

\begin{tabular}{c|c|c}
\hline Família Johnson & Função da transformação & Intervalo da função \\
\hline$S_{B}$ & $Y=\gamma+\eta \ln \left(\frac{X-\varepsilon}{\lambda+\varepsilon-X}\right)$ & $\eta, \lambda>0,-\infty<\gamma<\infty,-\infty<\varepsilon<\infty, \varepsilon<x<\varepsilon+\lambda$ \\
$S_{L}$ & $Y=\gamma+\eta \ln (X-\varepsilon)$ & $\eta>0,-\infty<\gamma<\infty,-\infty<\varepsilon<\infty, \varepsilon<x$ \\
$S_{U}$ & $Y=\gamma+\eta \operatorname{senh}^{-1}\left(\frac{X-\varepsilon}{\lambda}\right)$ & $\eta, \lambda>0,-\infty<\gamma<\infty,-\infty<\varepsilon<\infty,-\infty<x<\infty$ \\
\hline
\end{tabular}




\section{Resultados e discussões}

\section{Flexão simples}

$\mathrm{Na}$ Tabela 3 são apresentados os valores de densidade aparente $\left(\rho_{a p}\right)$, resistência $\left(f_{M, 12 \%}\right)$ e módulo de elasticidade à flexão com $12 \%$ de umidade $\left(E_{M, 12 \%}\right)$.

Pelos resultados de $P$-Value dos testes de normalidade apresentados na Tabela 3, não foi rejeitada a hipótese nula de que os dados provêm de distribuições normais.

A densidade aparente teve um coeficiente de variação condizente com resultados encontrados na literatura (Tabela 1), assim como seus valores mínimos, máximos e média.

O grau de dependência linear entre as variáveis $\rho_{a p}, f_{M, 12 \%}$ e $E_{M, 12 \%}$ foi estimado pelo coeficiente de correlação entre elas. Sendo o coeficiente de correlação $r$ entre a densidade e a resistência de 0,709, para a densidade e o módulo de elasticidade de 0,771 e entre a resistência e o módulo de elasticidade de 0,797 . A partir destes resultados, é possível observar que a correlação entre as três variáveis é razoavelmente alta e positiva, indicando que existe uma tendência considerável de valores mais altos de resistência e rigidez em amostras mais densas. Estes resultados são condizentes com os valores obtidos por Ballarin e Palma (2003) a partir da madeira do lenho adulto.

Aplicando-se o teste t Two sample com valores de resistência e rigidez das amostras de flexão, constatou-se que as médias obtidas neste estudo foram significantemente diferentes àquelas apresentadas pela literatura consultada (Tabela 1). Esta constatação também é a mesma ao se comparar os valores de literatura entre si.

\section{Compressão paralela às fibras}

Na Tabela 4 são apresentados os valores descritivos de densidade aparente $\left(\rho_{a p}\right)$, resistência $\left(f_{c 0,12 \%}\right)$ e módulo de elasticidade à compressão paralela às fibras $\left(E_{c 0,12 \%}\right)$ com valores estimados de $12 \%$ de umidade dos 16 corpos de prova da amostra, além de coeficientes de Poisson $\left(v_{L T}\right.$ e $\left.v_{L R}\right)$ para cinco corpos de prova.

Tabela 3 - Estatísticas descritivas dos resultados de densidade aparente, resistência e rigidez à flexão

\begin{tabular}{l|c|c|c}
\hline \multicolumn{1}{c|}{ Descrição } & $\begin{array}{c}\boldsymbol{\rho}_{a p} \\
(\mathrm{~kg} / \mathrm{m})\end{array}$ & $\begin{array}{c}\boldsymbol{f}_{\boldsymbol{M}, \mathbf{1 2} \%} \\
(\boldsymbol{M P a})\end{array}$ & $\begin{array}{c}\boldsymbol{E}_{\boldsymbol{M}, \mathbf{1 2} \%} \\
(\boldsymbol{M P a})\end{array}$ \\
\hline Mínimo & 520 & 61,6 & 10.409 \\
Máximo & 684 & 104,7 & 19.355 \\
Média & 592 & 78,2 & 14.029 \\
Desv. P. & 45 & 12,8 & 2.578 \\
Característico NBR 7190 & - & 65,6 & 10.489 \\
Característico BS EN 14358 & - & 55,0 & 13.608 \\
\hline COV (\%) & 7,64 & 16,39 & 18,38 \\
P-Value & 0,68 & 0,35 & 0,74 \\
\hline
\end{tabular}

Nota: CV: coeficiente de variação.

Tabela 4 - Estatísticas descritivas dos resultados de densidade aparente, resistência, rigidez e coeficientes de Poisson à compressão paralela às fibras

\begin{tabular}{|c|c|c|c|c|c|}
\hline Descrição & $\begin{array}{c}\rho_{a p} \\
\left(\boldsymbol{k g} f / m^{3}\right)\end{array}$ & $\begin{array}{l}f_{c 0,12 \%} \\
(M P a)\end{array}$ & $\begin{array}{l}E_{c 0,12 \%} \\
(M P a)\end{array}$ & $v_{L T}$ & $v_{L R}$ \\
\hline Mínimo & 510 & 37,2 & 12.907 & 0,43 & 0,20 \\
\hline Máximo & 650 & 56,9 & 25.606 & 0,62 & 0,42 \\
\hline Média & 597 & 47,5 & 18.828 & 0,53 & 0,34 \\
\hline Desv. P. & 40 & 6,7 & 3.348 & 0,08 & 0,09 \\
\hline Característico NBR 7190 & - & 41,0 & 15.658 & - & - \\
\hline Característico BS EN 14358 & - & 35,4 & 18.282 & - & - \\
\hline CV $(\%)$ & 6,65 & 14,11 & 17,78 & 14,95 & 26,79 \\
\hline P-Value & 0,64 & 0,31 & 0,30 & 0,71 & 0,53 \\
\hline
\end{tabular}

Nota: CV: coeficiente de variação. 
Conforme observado pelos resultados de $P$-Value apresentados na Tabela 4 , não foi rejeitada a hipótese nula para a distribuição normal dos resultados de densidade, resistência, rigidez e coeficientes de Poisson dos ensaios de compressão paralela às fibras.

Por meio do teste t Two sample, identificou-se que a média dos resultados encontrados a partir das amostras de compressão paralela se mostraram significativamente diferentes de todos aqueles apresentados pela literatura consultada (Tabela 1), com exceção do valor de exibido pela NBR 7190 (ABNT, 1997) a respeito da resistência $f_{c 0}$. Esta última comparação produziu um $P$-Value $=0,244$. Destaca-se que os resultados das propriedades da camada externa demonstraram ser significativamente superiores aos encontrados na literatura.

A correlação entre os resultados de densidade aparente $\left(\rho_{a p}\right)$, resistência $\left(f_{c 0}\right)$, módulo de elasticidade $\left(E_{c 0}\right)$ e coeficientes de Poisson $\left(v_{L T}\right.$ e $\left.v_{L R}\right)$ está apresentada na Tabela 5.

Dos coeficientes de correlação apresentados na Tabela 5, é possível identificar que as variáveis de densidade aparente, resistência e rigidez tiveram correlação positiva e relativamente alta. No entanto, quanto maiores foram os valores de densidade aparente e de resistência do corpo de prova, menores foram os valores de coeficientes de Poisson, com uma correlação média entre as variáveis. Entre os coeficientes de Poisson, constatou-se uma correlação medianamente alta e positiva. Quanto ao módulo de elasticidade, o aumento de seus valores produziu diminuição pouco significativa de $v_{L R}$ e aumento razoável de $v_{L T}$. De modo geral, os coeficientes de correlação envolvendo os coeficientes de Poisson indicam uma tendência de que quanto mais densos, rígidos e resistentes forem os corpos de prova pertencentes à amostra, menores serão as influências da deformação na direção paralela às fibras sobre as demais direções.

\section{Compressão normal às fibras}

Na Tabela 6 é apresentada a estatística descritiva dos resultados de densidade aparente $\left(\rho_{a p}\right)$, resistência $\left(f_{c 90,12 \%}\right)$ e módulo de elasticidade $\left(E_{c 90,12 \%}\right)$ com $12 \%$ de umidade dos 16 corpos de prova da amostra destinada à compressão normal às fibras, além de coeficientes de Poisson $\left(v_{T R}\right.$ e $\left.v_{T L}\right)$ obtidos a partir de resultados experimentais de cinco corpos de prova.

Todos os valores de $v_{T L}$ foram aproximadamente zero, indicando que as deformações passivas no sentido longitudinal às fibras decorrentes de esforços perpendiculares às fibras tendem a ser nulas ou desprezíveis para a amostra ensaiada.

Tabela 5 - Coeficientes de correlação entre as variáveis de densidade, resistência, módulo de elasticidade e coeficientes de Poisson dos ensaios de compressão paralela às fibras

\begin{tabular}{c|c|c|c|c|c}
\hline Variáveis & $\boldsymbol{\rho}_{a p}$ & $\boldsymbol{f}_{\boldsymbol{c} \boldsymbol{0}}$ & $\boldsymbol{E}_{\boldsymbol{c} \boldsymbol{0}}$ & $\boldsymbol{v}_{\boldsymbol{L} \boldsymbol{R}}$ & $\boldsymbol{v}_{\boldsymbol{L} \boldsymbol{T}}$ \\
\hline $\boldsymbol{\rho}_{\boldsymbol{a} \boldsymbol{p}}$ & 1,00 & 0,86 & 0,70 & $-0,50$ & $-0,44$ \\
$\boldsymbol{f}_{\boldsymbol{c} \boldsymbol{0}}$ & 0,86 & 1,00 & 0,73 & $-0,51$ & $-0,57$ \\
$\boldsymbol{E}_{\boldsymbol{c} \boldsymbol{0}}$ & 0,70 & 0,73 & 1,00 & $-0,18$ & 0,61 \\
$\boldsymbol{v}_{\boldsymbol{L} \boldsymbol{R}}$ & $-0,50$ & $-0,51$ & $-0,18$ & 1,00 & 0,70 \\
$\boldsymbol{v}_{\boldsymbol{L} \boldsymbol{T}}$ & $-0,44$ & $-0,57$ & 0,61 & 0,70 & 1,00 \\
\hline
\end{tabular}

Tabela 6 - Estatística descritiva dos resultados de densidade, resistência, rigidez e coeficientes de Poisson à compressão normal

\begin{tabular}{|c|c|c|c|c|c|}
\hline Descrição da Variável & $\begin{array}{c}\rho_{a p} \\
\left(k g f / m^{3}\right) \\
\end{array}$ & $\begin{array}{l}f_{c 90,12 \%} \\
(M P a) \\
\end{array}$ & $\begin{array}{c}E_{c 90,12 \%} \\
(M P a) \\
\end{array}$ & $v_{T R}$ & $v_{T L}$ \\
\hline Mínimo & 539 & 2,5 & 224 & 0,34 & 0,00 \\
\hline Máximo & 598 & 3,1 & 515 & 1,08 & 0,02 \\
\hline Média & 554 & 2,8 & 301 & 0,63 & 0,01 \\
\hline Desv. P. & 10 & 0,2 & 74 & 0,28 & 0,01 \\
\hline Característico NBR 7190 (ABNT, 1997) & - & 2,8 & $279 *$ & - & - \\
\hline Característico BS EN 14358 (COMITÉ..., 2016b) & - & 2,5 & $270 *$ & - & - \\
\hline CV $(\%)$ & 1,80 & 5,54 & 24,57 & 44,99 & 77,79 \\
\hline$P$-Value & 0,14 & 0,89 & 0,01 & 0,51 & 0,13 \\
\hline
\end{tabular}

Nota: CV: coeficiente de variação. *após a Transformação de Johnson (Eq. 11). 
Como o teste de normalidade dos dados de módulo de elasticidade de compressão normal resultou em um $P$ Value $=0,011$, a hipótese nula de normalidade deles foi rejeitada. Entre as distribuições avaliadas, a que obteve melhor ajuste foi a distribuição normal após a aplicação da transformação de Johnson.

No processo de transformação, a família $S_{L}$ foi estimada pelo melhor desempenho do $P$-Value, tendo como parâmetros $\gamma=-4,939, \eta=1,16915$ e $\varepsilon=209,905$. A função de transformação de Johnson para a família $S_{L}$ está presente na Tabela 2. O valor $\mathrm{Z}$ para o melhor ajuste foi de 0,31 , resultando em um $P$-Value de 0,684 , o que permite aceitar a hipótese nula dos novos dados serem representados por uma distribuição gaussiana. Na Figura 9 são apresentados os histogramas de distribuição dos resultados anteriores e posteriores ao tratamento, com suas respectivas curvas normais ajustadas.

Os valores característicos calculados conforme as normas brasileira e europeia apresentaram valores distintos para todas as propriedades avaliadas. A diferença média entre os valores (para mais ou para menos) ficou em torno de $13 \%$, sendo que a mais discrepante foi a referente ao módulo de elasticidade à flexão $\left(E_{M, k}\right)$, que foi $30 \%$ maior quando estimada pela norma europeia. O módulo de elasticidade à compressão normal às fibras $\left(E_{c 90, k}\right)$ calculado pela norma europeia ficou $3 \%$ menor em comparação com o calculado pela norma brasileira. Observa-se que no método brasileiro é empregado somente o resultado dos corpos de prova abaixo do segundo quartil para determinar o valor característico inferior, descartando-se possíveis valores extremos acima da mediana que venham a ser registrados via ensaios experimentais. Por sua vez, a norma europeia utiliza de todos os valores coletados, mas impõe que eles tenham sua distribuição com indícios de ajuste à uma distribuição normal ou lognormal.

Ao se analisar o comportamento da curva de força $\times$ deslocamento dos ensaios de compressão normal dos 16 corpos de prova, denotados por A1, A2 até A16 (Figura 10), foi observado que não há uma região inicialmente linear, como propõe a BS EN 408 (COMITÉ..., 2010). Desde os carregamentos iniciais, os pontos coletados apresentam tendência não linear.

A partir desta constatação, sugere-se que sejam considerados comportamentos não lineares da madeira, a fim de obter um maior refinamento e precisão da modelagem na análise e dimensionamento estrutural de placas de CLT produzidas por Pinus taeda. Em Vilela (2020), a modelagem numérica de placas de CLT submetidas à flexão considerando as propriedades elásticas lineares do Pinus taeda produziu resultados numéricos significativamente diferentes dos ensaios experimentais.

Figura 9 - Histogramas de distribuição para os resultados de $E_{c 90}$ com curvas de distribuição normal ajustadas aos resultados originais e modificados pela Transformação de Johnson (1949)

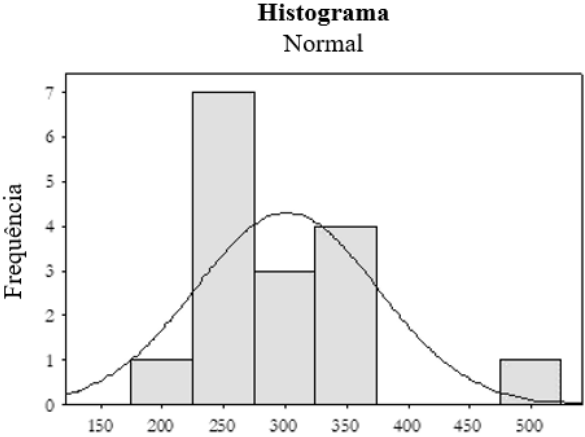

Módulo de Elasticidade Normal às fibras (MPa)

Histograma - Transformação de Johnson Normal

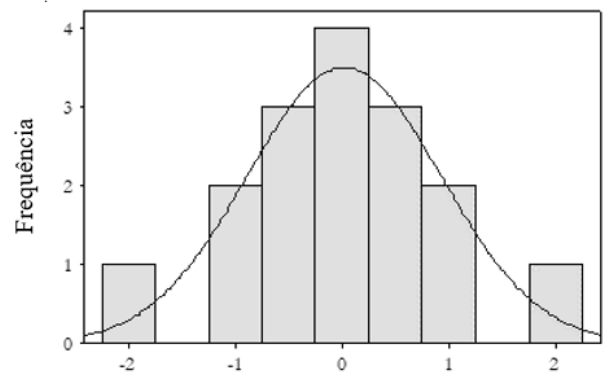

Módulo de Elasticidade Normal às fibras (MPa)

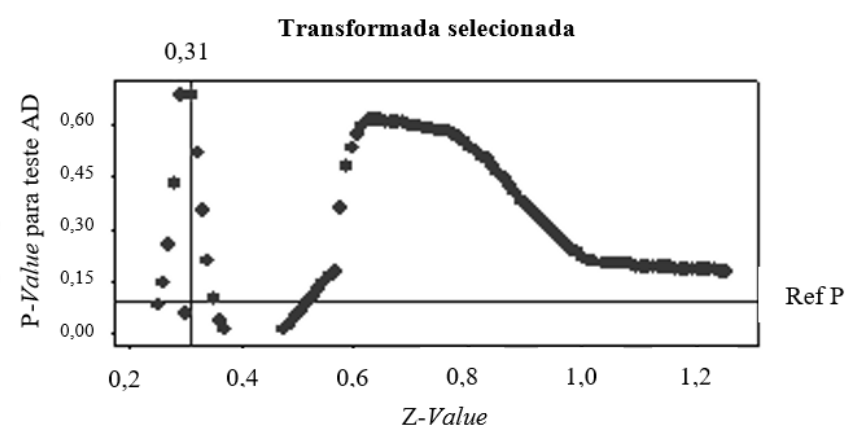

$\mathrm{P}-$ Value $=0,005$, média $<=0,005$

P-Value para melhor ajuste: 0,683938

Z para melhor ajuste: 0,31

Melhor família de transformação: $S_{L}$

Função de transformação igual:

$-4,93916+1,16919 \cdot \ln (X-209,903)$

102 Vilela, R.; Mascia, N. T. 
Figura 10 - Curvas de força $\times$ deslocamento dos ensaios de compressão normal às fibras

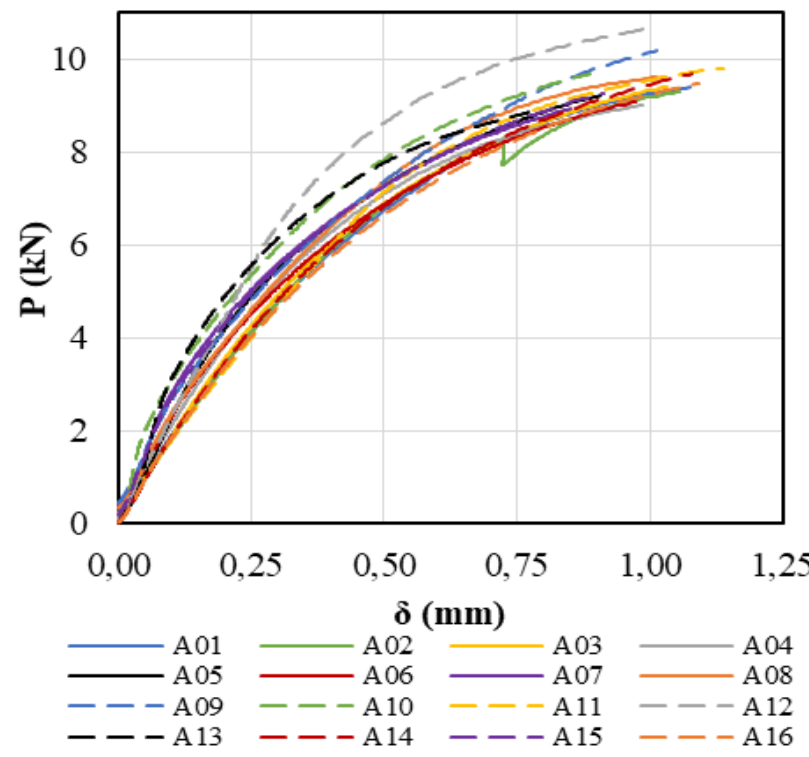

Alternativamente, na utilização de métodos analíticos para predizer a rigidez à flexão de placas de CLT tais como o método gama (PEREIRA; CARLITO JÚNIOR, 2015) ou a teoria de vigas de Timoshenko (THIEL, 2013) —, uma opção seria desconsiderar a contribuição da rigidez das camadas transversais. Esta prática também se justifica devido à existência de vazios (gaps) entre as faces laterais das camadas transversais, fazendo com que elas tenham pouca influência para a rigidez do composto. Assim sendo, este procedimento permite que o cálculo possa ser aplicado de maneira simplificada e conduz o projetista a resultados de deslocamentos e tensões a favor da segurança.

\section{Densidade}

Os dados obtidos de densidade se mostraram agrupados por tipo de amostra. Enquanto analisados por grupos separados, foi possível identificar ajustes aceitáveis para uma distribuição normal. No entanto, quando realizado o teste de normalidade para todos os pesos específicos aparentes, o $P$-Value foi inferior a 0,005 , permitindo confirmar a hipótese alternativa, ou seja, os dados não podem ser representados pela distribuição gaussiana. Quando avaliada a densidade dos corpos de prova de compressão paralela e flexão juntos, o $P$ Value estimado foi de 0,941 , indicando um alto nível de conformidade com a distribuição normal. Esta constatação se justifica pelo local de extração das amostras das placas de CLT, sendo as amostras de flexão e compressão paralela coletadas das faces externas, enquanto os corpos de prova da amostra de compressão normal às fibras foram extraídos de lamelas internas (Figura 3). Assim, a média da densidade das camadas externas é de $\bar{\rho}=594 \mathrm{~kg} / \mathrm{m}$, e o desvio padrão amostral $s_{\rho}=42 \mathrm{~kg} / \mathrm{m}$. Para as amostras coletadas das lamelas internas, a média aritmética da densidade encontrada é de $\bar{\rho}=554 \mathrm{~kg} / \mathrm{m}$, e o desvio padrão amostral $s_{\rho}=10 \mathrm{~kg} / \mathrm{m}$.

Ao aplicar o teste t Two sample aos valores advindos da amostra de compressão paralela e àqueles encontrados na literatura (Tabela 1), identificou-se que os resultados de $\rho_{a p}$ das camadas externas do CLT (considerando as amostras de compressão paralela e flexão) podem ser interpretados como estatisticamente não diferentes àqueles apresentados pela NBR 7190 (ABNT, 1997), $P$-Value $=0,108$, e também àqueles exibidos por Bendtsen e Senft (1986) e Ballarin e Nogueira (2005), $P$-Value =0,708 e 0,645. Por sua vez, os resultados de densidade $\rho_{a p}$ extraídos da amostra de camadas internas do CLT (corpos de prova compressão normal às fibras) assemelham-se aos apresentados por Ballarin e Palma (2003). As demais comparações das propriedades obtiveram $P$-Value $<\alpha$, portanto, estas médias são consideradas diferentes entre si.

Foi observado ainda que existem correlações consideráveis entre a densidade e as propriedades mecânicas de resistência e rigidez da espécie avaliada. Isto permite que, de forma indireta, a avaliação prévia da densidade da madeira seja um indicador para a classificação da resistência e rigidez do material. 


\section{Umidade}

Na Figura 11 é apresentado o diagrama de caixas (boxplot) dos resultados de umidade para os três tipos de amostras confeccionadas neste estudo. Nesta figura é possível identificar que os resultados de umidade das amostras da camada externa (flexão e compressão paralela às fibras) têm variações próximas, diferentemente dos resultados obtidos das amostras da camada interna.

$\mathrm{O}$ teste ANOVA foi realizado e identificou-se que o $F$-Value $=51,87$ ficou acima do valor $\mathrm{F}_{\text {crítico }}=3,20$, indicando que uma das amostras era significantemente diferente das outras no referente à umidade. Pelo método Bonferroni, constatou-se que as amostras das camadas externas não apresentaram diferenças significativas entre si, e que a umidade da amostra das camadas internas não pôde ser considerada igual às demais.

Além da diferença de densidade existente entre as amostras de diferentes camadas, notou-se uma considerável diferença no espaçamento dos anéis de crescimento, sendo que, as amostras das camadas internas apresentaram áreas maiores de lenho inicial ${ }^{3}$. Levando isto em consideração e sabendo que todas as amostras passaram por processo de secagem semelhante, pode-se inferir que um possível motivo para a diferença significativa de umidade da amostra de madeira interna do CLT estaria associado ao fato de a madeira menos densa ter uma sensibilidade maior à variação de umidade em função da alteração temperatura externa. Entretanto, estudos específicos devem ser conduzidos para ratificar esta constatação.

\section{Rupturas}

Na Figura 12 são apresentados os tipos de ruptura ocorridas nos corpos de prova dos ensaios de compressão normal às fibras.

Os corpos de prova submetidos a compressão normal às fibras, em geral, apresentaram deformações excessivas tanto no sentido do carregamento (esmagamento) quanto na direção transversal (alargamento), além de distorções visíveis a olho nu (Figura 12a). Estas deformações inelásticas não limitavam o carregamento, mesmo com incremento de deslocamento aplicado pelo atuador. Em 56\% dos casos, com o incremento de deslocamento após o carregamento máximo, verificou-se fendilhamento ao redor dos anéis de crescimento (Figura 12b) causado pelo alargamento excessivo da seção transversal.

Figura 11 - Diagrama de caixas dos resultados de umidade as amostras de flexão, compressão paralela e compressão normal às fibras

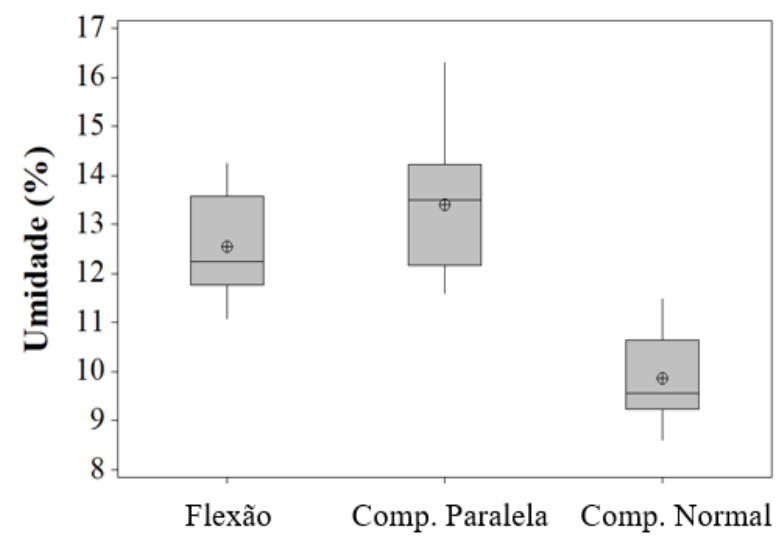

${ }^{3}$ Madeira constituída por células que nascem em estações de primavera/verão. Pelas condições climáticas favoráveis ao seu crescimento, estas células têm seção transversal maior e parede celular menor, proporcionando menores densidade, rigidez e resistência desta região.

104 Vilela, R.; Mascia, N. T. 
Figura 12 - Tipos de ruptura à compressão normal às fibras: (a) corpo de prova com deformações visíveis a olho nu; (b) fendilhamento ao redor dos anéis de crescimento

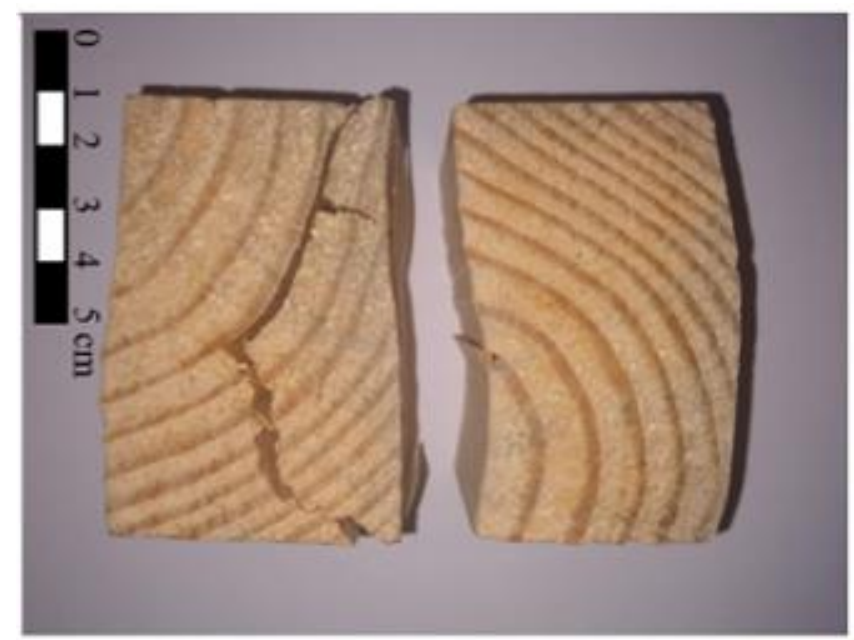

(a)

(b)

Dos tipos de ruptura à compressão paralela às fibras, $25 \%$ dos corpos de prova apresentaram esmagamentos aproximadamente no meio dos corpos de prova (Figura 13a), 50\% dos corpos de prova apresentaram fissuras características de esmagamento próximas à extremidades (Figura 13b) e 25\% dos corpos de prova apresentaram deformações na extremidade tipo "vassoura" (brooming) (Figura 13c), onde as fibras do topo inclinam-se para o lado, fazendo com que os deslocamentos impostos pelo atuador não resulte em incrementos de carga (BODIG; JAYNE, 1982).

$\mathrm{Na}$ flexão, os corpos de prova sofreram rupturas sempre na metade do vão em sua região inferior. Na face superior das vigas, ocorreram deformações devido ao embutimento do rolete atuador, sendo estas deformações mais acentuadas nos corpos de prova que suportaram maior carregamento (Figura 14a). As rupturas características de flexão na tração foram observadas nos corpos de prova, tais como deslocamento de topo das fibras formando uma fissura perpendicular à seção transversal, até aproximadamente a metade da seção (Figura 14b); lascamento na parte inferior do meio do vão, ocorrido em peças onde houve leve inclinação das fibras (Figura 14c). Em corpos de prova em que a fissura teve maior propagação, observou-se ainda uma bifurcação da mesma (Figura 14d).

\section{Classes normativas}

A norma técnica brasileira NBR 7190 (ABNT, 1997) e a europeia BS EN 338 (COMITÉ..., 2016a) contam com tabelas para classificação da madeira para fins de projeto. Quanto à classificação, estas normas se distinguem não somente pela quantidade de classes que abrangem, mas também pelo valor das propriedades consideradas por cada uma delas.

Considerando o valor de resistência $\left(f_{c 0, k}\right)$ e o módulo de elasticidade $\left(E_{c 0, m}\right)$, as amostras de Pinus taeda provenientes das camadas externas devem ser classificadas como a maior classe de coníferas para a norma brasileira - a classe C30. A ressalva observada para esta classificação se relaciona com a densidade aparente média, que experimentalmente teve um valor cerca de $1 \%$ abaixo do valor indicado para esta classe normativa. As outras propriedades dos ensaios ficaram $30 \%\left(E_{c 0, m}\right)$ e $37 \%\left(f_{c 0, k}\right)$ acima da classe estabelecida, e são valores consideravelmente elevados.

Para a norma europeia, o material utilizado nas camadas externas também é classificado como o de maior classe para uma softwood - no caso, a classe C50. Para isto, são considerados os valores de densidade média $\left(\rho_{a p, m}\right)$, resistência à flexão e compressão $\left(f_{m, k}\right.$ e $\left.f_{c 0, k}\right)$ e módulo de elasticidade à flexão $\left(E_{m, k}\right)$. Os valores calculados a partir dos experimentos ficam $7 \%, 9 \%, 18 \%$ e $21 \%$, respectivamente, acima dos valores da classe, o que representa uma diferença significativa. 
Figura 13 - Tipos de ruptura à compressão paralela às fibras: (a) esmagamento aproximadamente no meio dos corpos de prova; (b) fissuras características de esmagamento próximas às extremidades; (c) deformações na extremidade tipo "vassoura"

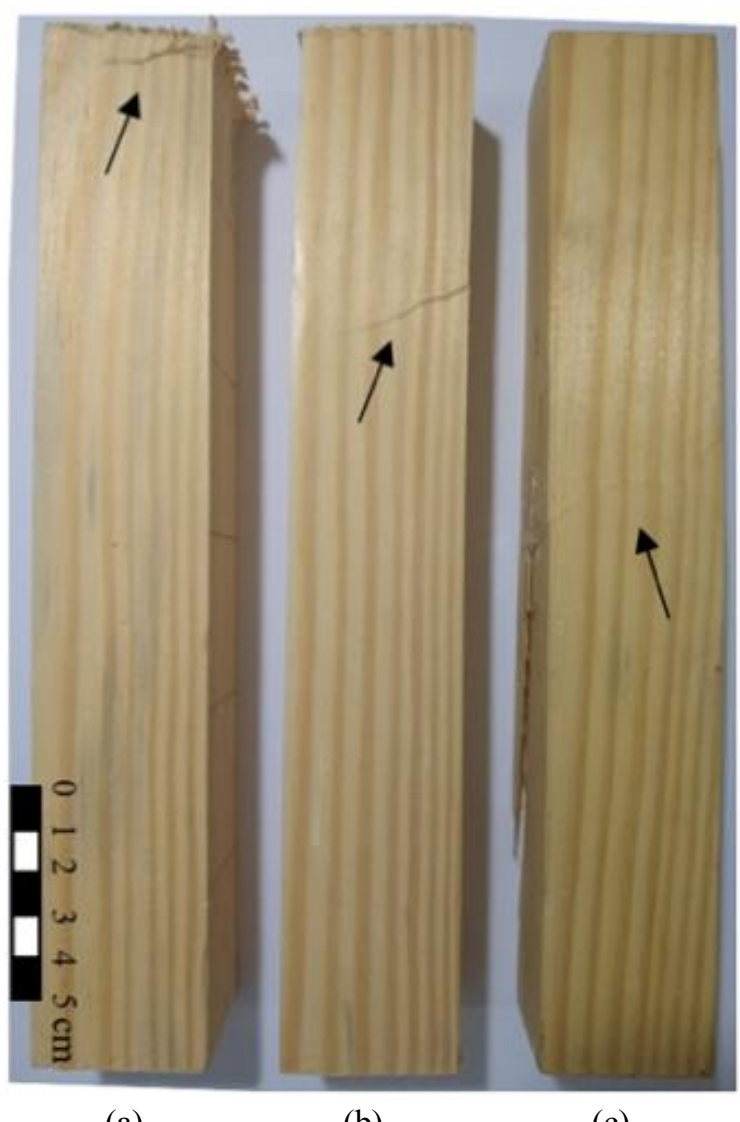

(a)

(b)

(c)

Figura 14 - Rupturas comum dos corpos de prova ensaiados à flexão

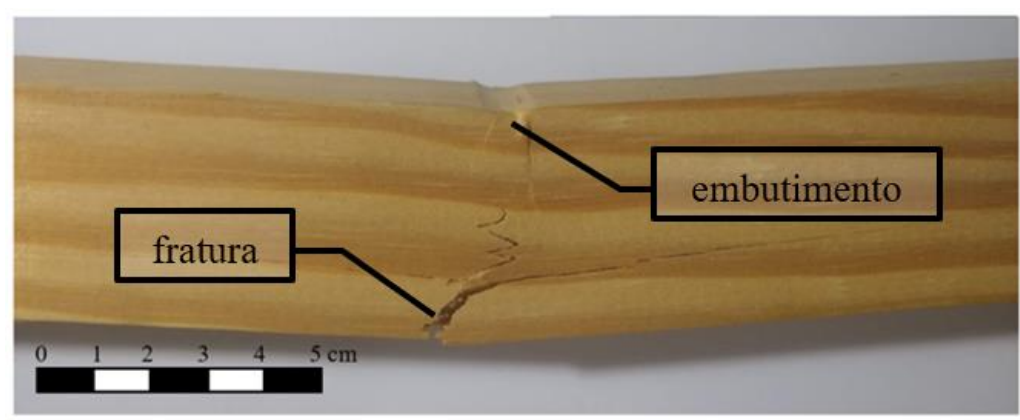

(a)

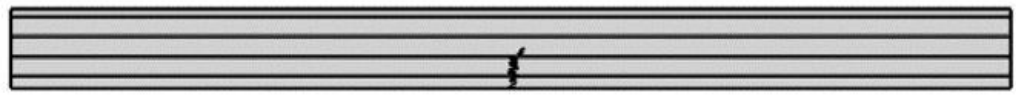

(b)

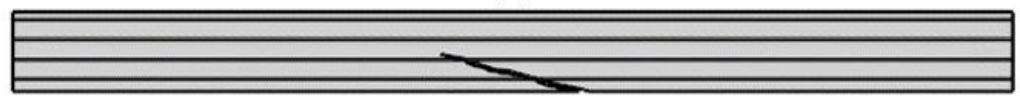

(c)

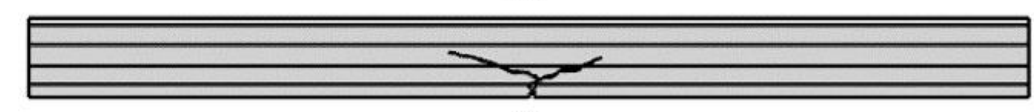

(d) 
A madeira empregada nas camadas internas, segundo a norma brasileira, tem sua classificação como C20, a menor classe para coníferas. Este resultado é obtido indiretamente pela relação estabelecida pela própria norma brasileira $\left(E_{c 0}=20 \cdot E_{c 90}\right)$. Entretanto, para a resistência, utilizando a relação $f_{c 0, k}=4 \cdot f_{c 90, k}$, foi obtido um valor de $11 \mathrm{MPa}$, aproximadamente a metade do estabelecido para esta classe (20 MPa). Considerando que a resistência à compressão normal às fibras não é prioritária nas rupturas iniciais do CLT $^{4}$ e, sim, o módulo de elasticidade destas camadas. Por este motivo, esta última propriedade foi considerada para a classificação da madeira proveniente das camadas internas. Caso a classificação fosse parametrizada pela resistência à compressão paralela (indiretamente), seria alcançado o valor de $E_{c 90} 39 \%$ abaixo do valor encontrado experimentalmente.

Por sua vez, segundo a norma europeia, a classe C18 é a que melhor classifica a madeira empregada nas camadas internas. Esta classificação é realizada levado em consideração valores de densidade $\left(\rho_{a p, m}\right)$, resistência $\left(f_{c 90, k}\right)$ e elasticidade $\left(E_{c 90, m}\right)$. Para estas propriedades, a diferença entre os ensaios e os valores normativos é de $42 \%, 12 \%$ e $1 \%$, respectivamente, a favor da segurança, porém, consideravelmente elevados.

É importante destacar que a classificação sugerida pela norma europeia é estabelecida pela resistência à flexão da madeira, e que, segundo a norma brasileira em vigor, a classificação deve ser estimada pela resistência à compressão paralela às fibras. Entretanto, neste estudo as classes das camadas internas foram deduzidas indiretamente pela relação de cada norma entre módulo de elasticidade normal às fibras e suas respectivas propriedades principais de classificação.

Na BS EN 408 (COMITÉ..., 2010), pressupõe-se que o trecho compreendido entre 10\% e 40\% do carregamento máximo estimado produza deformações lineares no material, por isso, determina-se um modulo de elasticidade para compressão normal $\left(E_{c 90}\right)$ constante. Entretanto, de modo geral, os corpos de prova apresentaram uma relação não linear entre deslocamento e força (Figura 10). Este comportamento seria mais precisamente representado por uma função não linear (por exemplo, polinomial de segundo grau ou bilinear). Porém, não há evidências suficientes para garantir que tal comportamento não possa ser resultado do posicionamento do extensômetro em uma região muito próxima ao apoio, onde pode haver perturbação de tensões e deformações.

A utilização de classes estruturais para a madeira é uma prática comum entre as normas técnicas. A classificação da madeira aufere produtividade na fase de projeto e aumenta o controle de qualidade no processo de fabricação das lamelas. Mesmo porque, como apresentado ao longo deste item, amostras de uma mesma espécie podem ter classificações diferentes perante uma mesma norma. Entretanto, também é demonstrado que existe uma diferença considerável de diversas propriedades características estimadas experimentalmente com valores propostos pelas classes normativas, que, por sua vez, pretendem atender as diversas espécies de madeira que possam ser utilizadas estruturalmente. Uma alternativa para reduzir as incertezas do projeto quanto à probabilidade das características físicas e mecânicas da madeira está direcionada ao emprego de técnicas de confiabilidade para a análise e dimensionamento de tais estruturas.

\section{Conclusões}

Este trabalho teve por objetivo avaliar resultados experimentais de amostras extraídas de placas industrializadas de CLT produzidas com madeira da espécie Pinus taeda a partir de ensaios de compressão paralela e normal às fibras e ensaios de flexão. Com base nas análises realizadas, destacam-se as conclusões apresentadas a seguir.

Os resultados de densidade, módulos de elasticidade e resistência obtidos se ajustaram adequadamente à distribuição gaussiana para os três tipos de ensaios. Entretanto, os resultados de módulo de elasticidade à compressão normal às fibras $\left(E_{c 90}\right)$ passaram pela transformação de Johnson para se ter um bom ajuste à distribuição gaussiana. Ao alterar o $P$-Value inicial de 0,011 para 0,684 , a transformação de Johnson se mostrou eficaz no tratamento estatístico dos resultados de $E_{c 90}$, permitindo que estes possam ser representados por uma curva de distribuição gaussiana.

${ }^{4}$ As placas de CLT ensaiadas na flexão tiveram suas rupturas iniciais ocasionadas por dois motivos: rompimento à tração de regiões onde havia ligações de topo finger joints de camadas externas submetidas ao máximo momento fletor; e/ou fissuras em formatos ondulares de camadas transversais onde o esforço cortante provocava maiores tensões de cisalhamento. 
O comportamento não linear da relação tensão $\times$ deformação e, consequentemente, do módulo de elasticidade na direção normal às fibras foi observado, demonstrando que a hipótese assumida pela norma BS EN 408 (COMITÉ..., 2010) não deve ser adotada indiscriminadamente. Por esta razão, sugere-se que na modelagem do comportamento estrutural do CLT com Pinus taeda seja considerada a não linearidade da rigidez das camadas sujeitas a tensões referentes à compressão normal às fibras quando for requerida uma precisão mais adequada do comportamento estrutural de tais elementos ou que seja desconsiderada a contribuição de rigidez das camadas transversais devido às lacunas entre lamelas ou fissuras que interrompem a transmissão de tensões e deformações ao longo destas camadas.

Os coeficientes de correlação de Pearson entre as variáveis obtidas experimentalmente neste estudo evidenciaram que, de modo geral, quanto maior é a densidade do corpo de prova do Pinus taeda, maiores tendem a ser os valores de resistência e rigidez e menores tendem a ser os valores dos coeficientes de Poisson. Esta constatação confirma a hipótese inicial de que existem relações significantes entre as propriedades mecânicas e de densidade da madeira de Pinus taeda.

A classificação sugerida para as amostras avaliadas é C50 e C18 para as camadas externas e internas, respectivamente, conforme a norma europeia BS EN 338 (COMITÉ..., 2016a). Para as classes estabelecidas conforme a norma brasileira NBR 7190 (ABNT, 1997), as camadas externas ficam classificadas como C30 e as internas, como C20. Há ressalvas para a classificação das lamelas internas, para a qual se sugere realizar ensaios diretos de compressão paralela às fibras e de flexão para maior confiança da classificação segundo as normas avaliadas.

Avaliando os resultados obtidos pela literatura citada e por este estudo, constata-se que as propriedades mecânicas e de densidade do Pinus taeda em idades distintas e provenientes de diversas regiões de plantação apresentam diferenças consideráveis entre si. Como tais propriedades são fundamentais para a análise e predição do comportamento mecânico de elementos como o CLT, recomenda-se que avaliações de controle de qualidade sejam realizadas regularmente em amostras de lotes destinados a estes produtos.

Os resultados de propriedades mecânicas e de densidade obtidos experimentalmente comparados aos valores encontrados nas classes de ambas as normas mostraram diferenças significativas, mesmo que conservadoras. Isto demonstra que, apesar de as classes serem divididas em coníferas e folhosas, existe uma grande quantidade de espécies englobadas nestas tipologias, o que muitas vezes causa representações com baixa assertividade. Alternativamente, os valores de propriedades mecânicas e de densidade apresentados neste estudo podem ser empregados em projetos de placas de CLT considerando a diferença de materiais entre as camadas por métodos analíticos, numéricos ou estocásticos.

\section{Referências}

ALBINO, F. S. Efeito da força cortante nos deslocamentos de vigas de madeira sujeitas à flexão estática. Campinas, 2013. Dissertação (Mestrado em Engenharia Civil) - Universidade Estadual de Campinas, Campinas, 2013.

ALMEIDA, D. H. de et al. Comparação das resistências ao embutimento paralelo às fibras de madeiras de pínus oocarpa, cumaru e pínus taeda. Ambiente Construído, Porto Alegre, v. 14, n. 3, p. 113-119, jul./set. 2014.

AMERICAN NATIONAL STANDARD INSTITUTE; AMERICAN PLYWOOD ASSOCIATION. PRG320: standard for performance-rated cross-laminated timber. New York, 2018.

ANDERSON, T. W.; DARLING, D. A. Asymptotic theory of certain "Goodness of Fit" criteria based on stochastic processes. The Annals of Mathematical Statistics, v. 23, n. 2, p. 193-212, jun. 1952.

ASSOCIAÇÃO BRASILEIRA DE NORMAS TÉCNICAS. NBR 7190: projeto de estruturas de madeira. Rio de Janeiro, 1997.

BALLARIN, A. W.; NOGUEIRA, M. Determinação do módulo de elasticidade da madeira juvenil e adulta de Pinus taeda por ultra-som. Engenharia Agrícola, v. 25, n. 1, p. 19-28, abr. 2005.

BALLARIN, A. W.; PALMA, H. A. L. Propriedades de resistência e rigidez da madeira juvenil e adulta de Pinus taeda L. Revista Árvore, v. 27, n. 3, p. 371-380, jun. 2003.

BAÑO, V. et al. Characterization and Structural Performance in Bending of CLT Panels Made from SmallDiameter Logs of Loblolly/Slash Pine. Materials, v. 11, n. 12, p. 2436, nov. 2018. 
BENDTSEN, B. A.; SENFT, J. Mechanical and anatomical properties in individual growth rings of plantation-grown Eastern Cottonwood and Loblolly Pine. Wood and Fiber Science, v. 18, p. 16, 1986.

BODIG, J.; JAYNE, B. A. Mechanics of wood and wood composites. New York: Van Nostrand, 1982.

BONFERRONI, C. E. Teoria statistica delle classi e calcolo delle probabilità. Pubblicazioni del R Istituto Superiore di Scienze Economiche e Commerciali di Firenze, v. 8, p. 3-62, 1936.

BUCK, D. et al. Bending properties of Cross Laminated Timber (CLT) with a $45^{\circ}$ alternating layer configuration. BioResources, v. 11, n. 2, p. 4633-4644, 2016.

COMITÉ EUROPÉEN DE NORMALIZATION. BS EN 14358: calculation and verification of characteristic values. Brussels, $2016 \mathrm{~b}$.

COMITÉ EUROPÉEN DE NORMALIZATION. BS EN 338: structural timber: strength classes. Brussels, $2016 \mathrm{a}$.

COMITÉ EUROPÉEN DE NORMALIZATION. BS EN 408: timber structures: structural timber and glued laminated timber: determination of some physical and mechanical properties. Brussels, 2010.

GILLIS, C. M.; STEPHENS, W. C.; PERALTA, P. N. Moisture meter correction factors for four Brazilian wood species. Forest Products Journal, v. 51, n. 4, p. 83-83, 2001.

INDÚSTRIA BRASILEIRA DE ÁRVORES. Relatório Anual 2019. 2019. Disponível em: https://iba.org/datafiles/publicacoes/relatorios/iba-relatorioanual2019.pdf. Acesso em: 11 fev. 2021.

IZZI, M.; POLASTRI, A.; FRAGIACOMO, M. Investigating the hysteretic behavior of cross-laminated timber wall systems due to connections. Journal of Structural Engineering, v. 144, n. 5, 2018.

JELEČ, M.; VAREVAC, D.; RAJČIĆ, V. Cross-laminated timber (CLT): a state of the art report. Journal of the Croatian Association of Civil Engineers, v. 70, n. 02, p. 75-95, 2018.

JEONG, G. Y.; HINDMAN, D. P.; ZINK-SHARP, A. Orthotropic properties of loblolly pine (Pinus taeda) strands. Journal of Materials Science, v. 45, n. 21, p. 5820-5830, 2010.

JOHNSON, N. L. Systems of frequency curves generated by methods of translation. Biometrika, v. 36, n. 1/2, p. 149-176, 1949.

LI, T. et al. Correction Factors for a radio frequency-type moisture meter for heat-treated wood.

BioResources, v. 8, n. 4, p. 5549-5560, 2013.

MANNINEN, H. Long-term outlook for engineered wood products in Europe. European Forest Institute, 2014. Disponível em: https:/www.efi.int/sites/default/files/files/publication-bank/2018/tr_91.pdf. Acesso em: 29 maio. 2019.

MASCIA, N. T.; LAHR, F. A. R. Remarks on orthotropic elastic models applied to wood. Materials Research, v. 9, n. 3, p. 301-310, 2006.

MASCIA, N. T.; VANALLI, L. Evaluation of the coefficients of mutual influence of wood through off-axis compression tests. Construction and Building Materials, v. 30, p. 522-528, 2012.

MILOTA, M. R. Specific gravity as a predictor of species correction factors for a capacitance-type moisture meter. Forest Products Journal, v. 44, n. 3, p. 63, 1994.

MOYA, L. et al. Physical and Mechanical Properties of Loblolly and Slash Pine Wood from Uruguayan Plantations. Forest Products Journal, v. 63, n. 3-4, p. 128-137, 2013.

MURTA, A. et al. Benefícios económicos e ambientais inerentes ao uso de materiais estruturais naturais em habitações unifamiliares. Ambiente Construído, Porto Alegre, v. 10, n. 3, p. 7-22, jul./set. 2010.

OLIVEIRA, G. L. Cross Laminated Timber (CLT) no Brasil: processo construtivo e desempenho. São Paulo, 2018. Dissertação (Mestrado em Arquitetura e Urbanismo) - Universidade de São Paulo, São Paulo, 2018.

PEREIRA, M. C. de M.; CALIL JUNIOR, C. Strength and stiffness of Cross Laminated Timber (CLT) panels produced with Pinus and Eucalyptus: experimental and analytical comparisons. Matériab, v. 24, n. 2, 2019. 
PEREIRA, M. C. de M.; CARLITO JÚNIOR, C. Aplicação do método gama para dimensionamento de elementos de lajes de CLT. In: ENCONTRO BRASILEIRO EM MADEIRAS E ESTRUTURAS DE MADEIRA, 15., Curitiba, 2015. Anais [...] Curitiba: 2015.

RUY, M. et al. Ultrasound grading of round Eucalyptus timber using the Brazilian standard. European Journal of Wood and Wood Products, v. 76, n. 3, p. 889-898, 2018.

RYAN, B. F.; CRYER, J. D.; JOINER, B. L. Minitab handbook: updated for release 16. Brooks/Cole, 2013.

SCHULTZ, R. P. Loblolly pine: the ecology and culture of loblolly pine (Pinus taeda L.). In: AGRICULTURE Handbook. New Orleans: U.S. Department of Agriculture, Forest Service, 1997.

THIEL, A. ULS and SLS design of CLT and its implementation in the CLTdesigner: Focus Solid Timber Solution. In: EUROPEAN CONFERENCE ON CROSS LAMINATED TIMBER (CLT). Austria: Graz University of Technology, 2013.

VILELA, R. Desempenho estrutural de placas de Cross Laminated Timber submetidas à flexão. Campinas, 2020. Dissertação (Mestrado em Engenharia Civil) - Universidade Estadual de Campinas, Campinas, 2020.

\title{
Agradecimentos
}

Os autores agradecem à Faculdade de Engenharia Agrícola (FEAGRI) da Universidade Estadual de Campinas (Unicamp) pela disponibilização de equipamentos e funcionários para a condução dos ensaios experimentais realizados no Laboratório de Materiais e Estruturas (LME), à Crosslam pelo fornecimento de materiais e equipamentos e à Coordenação de Aperfeiçoamento de Pessoal de Nível Superior (CAPES) pela concessão de bolsa de estudos (nº 05-P-04797-2019).

Ramon Vilela

Departamento de Estruturas | Universidade Estadual de Campinas | Rua Saturnino de Brito, 224 | Campinas - SP - Brasil | CEP 13083-889 | Tel.: (19) 99101-7745 | E-mail: ramonvilela@outlook.com

Nilson Tadeu Mascia

Departamento de Estruturas | Universidade Estadual de Campinas | Tel.: (19) 3521-2302 | E-mail: ntm@unicamp.br

\author{
Ambiente Construído \\ Revista da Associação Nacional de Tecnologia do Ambiente Construído \\ Av. Osvaldo Aranha, $99-3^{\circ}$ andar, Centro \\ Porto Alegre - RS - Brasil \\ CEP 90035-190 \\ Telefone: +55 (51) 3308-4084 \\ www.seer.ufrgs.br/ambienteconstruido \\ www.scielo.br/ac \\ E-mail: ambienteconstruido@ufrgs.br
}

